\title{
India's Contribution to Geomagnetism and Allied Studies in Antarctica
} - A Review

\author{
ASHWINI K SINHA ${ }^{1, *}$, AJAY DHAR ${ }^{1}$, ANAND K SINGH ${ }^{2}$, JAYANTA K BEHERA ${ }^{1}$ and \\ S GURUBARAN ${ }^{1}$ \\ ${ }^{1}$ Indian Institute of Geomagnetism, Plot 5, Sector 18, New Panvel (W), Navi Mumbai 410 218, India \\ ${ }^{2}$ ESSO-NCAOR, Goa, India
}

(Received on 14 May 2016; Accepted on 14 December 2016)

\begin{abstract}
In this paper, we review the progress in Geomagnetism and allied areas based on the past thirty five Indian Antarctic expeditions and summarize the scientific results obtained in the last decade. Various dynamic processes in the near-Earth space environment, driven by the transient changes in geomagnetic field such as storms and substorms, severely affect the space weather over the Polar Regions. Magnetopsheric substorms lead to the intensification of ionospheric currents and auroral outbursts within the auroral oval, causing energetic charged particles in the auroral region to come down to D-region ionosphere, which is reflected as Cosmic Noise Absorption (CNA) as monitored by imaging RIOmeter at Indian Antarctic station, Maitri (Geog. $70.75^{\circ} \mathrm{S}, 11.73^{\circ} \mathrm{E}$; Geom. $\left.66.84^{\circ} \mathrm{S}, 56.29^{\circ} \mathrm{E}\right)$. A systematic rapid decline in The Earth's complex main magnetic field at Maitri ( 110 nT/yr) is important for monitoring the evolution of reverse magnetic flux patches due to physical processes occurring in the outer core of the Earth. The Global Electric Circuit (GEC) studies were started to understand the solar-terrestrial relationship and associated changes in surface weather and the near-earth electrical environment. Schumann resonances (SRs), the AC part of GEC reveal a strong UT variation of amplitude in seasonal as well as yearly time scales. The observed diurnal variation is explained in terms of the dominant thunderstorm activity centered over the three convectively active regions, viz. Asia/Maritime Continent (Indonesia), South America and Africa.

The velocity and strain distribution of Schirmarchaer Glacier was investigated during two GPS campaigns in the year 2003 and 2004. The studies indicate that the horizontal velocity is in the range of $1.89-10.88 \mathrm{ma}^{-1}$ with an average velocity of $6.21 \mathrm{ma}^{-1}$.
\end{abstract}

\section{Keywords: Indian Institute of Geomagnetism (IIG); Indian Antarctic Research Stations; Geomagnetism; Global Electric Circuit; GPS; Environmental Magnetic Studies}

\section{Introduction}

Antarctica is a region of great importance for studies of geomagnetism and allied fields. Present day geometry of the Earth's main magnetic field causes the high latitude region of the atmosphere to be directly affected by the increase in magnetospheric energy during geomagnetic storms and substorms. Intense energy input from the magnetosphere can result in visually spectacular aurora and changes in the ionosphere that affect HF (high frequency) communication (Detrick and Rosenberg, 1990). Increase in the convective electric field and auroral particle precipitation produce intense currents in the

*Authorfor Correspondence: E-mail: sinha.ashwini@gmail.com ionosphere, which are monitored through magnetic field measurements (Singh et al., 2012; Behera et al., 2015). Changes in the ionosphere are also monitored using an Imaging Riometer, which measures the strength of the $38.2 \mathrm{MHz}$ galactic radio waves that impinge on the Earth's atmosphere, and thereby gives information on the changes in absorption of this signal due to changes in the ionospheric electron density (Browne et al., 1995). Apart from the dramatic short term changes in the geomagnetic field recorded at Antarctica, which may be attributed to external causes, it has emerged that the Earth's complex main magnetic field, which has its origin in the fluid outer core of the Earth at a depth of about 
$2900 \mathrm{~km}$ below the surface of the Earth, is also undergoing a systematic rapid decline as observed in the Antarctic region (Pathan et al., 2009). Indian Institute of Geomagnetism (IIG) started geomagnetic field measurements in Antarctica during the first Indian Antarctic Expedition in 1981-82. With the setting up of a permanent base at Dakshin Gangotri (DG) in 1983-84, observations were taken on a regular basis with Proton Precession Magnetometer (PPM), Fluxgate Magnetometer and an $30 \mathrm{MHz}$ Analogue Riometer (Rajaram et al., 2001). After abandoning of Dakshin Gangotri Station and construction of new Station at Maitri in 1990, the observations were continued at Maitri and additional instruments were deployed. The Fluxgate Magnetometer was replaced by Digital Fluxgate Magnetometer (DFM) and the 30 $\mathrm{MHz}$ Riometer by a $38.2 \mathrm{MHz}$ Imaging Riometer. The observations have indicated the importance of the location of Maitri, as a sub-auroral during magnetically quiet periods. However, during magnetically disturbed times auroral oval expands and the variations recorded are quite different from their quiet time variations. Large decrease in the main magnetic field observed at Maitri are now emerging to be important for monitoring the evolution of reverse magnetic flux patches due to physical processes occurring in the molten conducting outer core of the Earth. The study of Global Electric Circuit (GEC) provides a platform for understanding the solarterrestrial relationship and associated changes in surface weather. Continuous measurements are carried out to understand the near-earth electrical environment. A link could be established between the surface electrical environment and space weather events (Panneerselvam et al., 2010; Jeni et al., 2015).

The Indian Antarctic Geomagnetic studies commenced with the launching of the first Indian Antarctic expedition in 1981-82. The first Indian base was set up in the Queen Maud Land region (Geog. $70^{\circ} \mathrm{S}$ latitude, $12^{\circ} \mathrm{E}$ longitude) of east Antarctic ice shelf. Nearly 10 days of magnetic data were collected with a PPM in January 1982. Since then, the stay and the observational period kept on increasing with setting up of permanent stations, Dakshin Gangotri (1983) and Maitri (1990). The third Indian Antarctic Station, Bharati (Geog. Co-ordinates $\sim 69^{0} \mathrm{~S}, 76^{\circ} \mathrm{E}$ ) was commissioned at Larsemann Hills, East Antarctica in the year 2012. Over the past 35 years, the magnetic field is being continuously monitored, except for a few years gap in between. The geographic location of Dakshin Gangotri and Maitri has proved to be unique location from geomagnetic point of view, as will be elaborated in the results and discussions. With barely 2\% of Antarctic Continent free from ice, Maitri is located on one such ice-free rocky area of Schirmacher Oasis - with number of fresh water lakes available within this area.

The present review on Geomagnetism and allied aspects is based on the past Indian Antarctic expeditions and summarizes the observations along with their scientific implications.

\section{Experimental Facilities}

IIG is participating in the Indian Scientific Expedition to Antarctic (ISEA) since its inception and fair numbers of scientists have visited Antarctica. The Institute is conducting geomagnetic, ionospheric, airearth current and GPS measurements in Antarctica. The following instruments were operated for various geophysical studies as mentioned above:

i. Proton Precession Magnetometer (PPM) for recording of Total Magnetic Field (F) intensity

ii. Fluxgate Magnetometer (FM) to record variations in the three orthogonal components $\mathrm{X}, \mathrm{Y}$ and $\mathrm{Z}$. The Fluxgate Magnetometer was later replaced by a Digital Fluxgate Magnetometer (DFM) in 2003.

iii. $\quad 30 \mathrm{MHz}$ Riometer to measure the strength of the cosmic radio noise that impinge on the Earth's atmosphere, causing secondary ionization in the D region. The Riometer was replaced by an Imaging Riometer operated at 38.2 MHz to have a better understanding of the absorption processes

iv. Magnetometers at the vertices's of a triangle to determine the velocity of small-scale auroral current systems over Maitri

v. Maxwell Current experiment to determine variations in air earth current system. The system was later expanded to record all three parameters of Global Electric Circuit (GEC), namely Conduction Current, Potential Gradient and AirEarth Current. An Automatic Weather Station (AWS) was also operated to record Meteorological parameters used in analysis of GEC data

vi. Global Positioning System (GPS) for studies of crustal deformation and Glacier movement 
vii. Induction Coil Magnetometer (ICM) for monitoring geomagnetic field variations in 0-32 $\mathrm{Hz}$ frequency range (geomagnetic pulsations). The Schumann Resonance frequencies estimated from the data set provide information about the global temperature and global change in temperature operated on a long-term basis.

\section{Major Scientific Achievements}

\section{Comparative study of Quiet Day variations at Dakshin Gangotri (DC) and Novolazarevskaya (NOVO)}

Regular geomagnetic measurements were started after establishing of Dakshin Gangotri Station during 1983-84. A comparative study of the quiet day features of the geomagnetic field at DG and nearby Russian Station, Novolazarevskaya was carried out to check the validity of data. The mean diurnal variation pattern of the three magnetic elements at the two stations (Fig. 1A) show that the two stations are in close conformity with the anticipated diurnal patterns for such geographical locations during local summer months close to solar minimum epoch. The range of variations at both stations is nearly the same.

However, the departures from total coincidence can be mainly attributed to the fact that the three
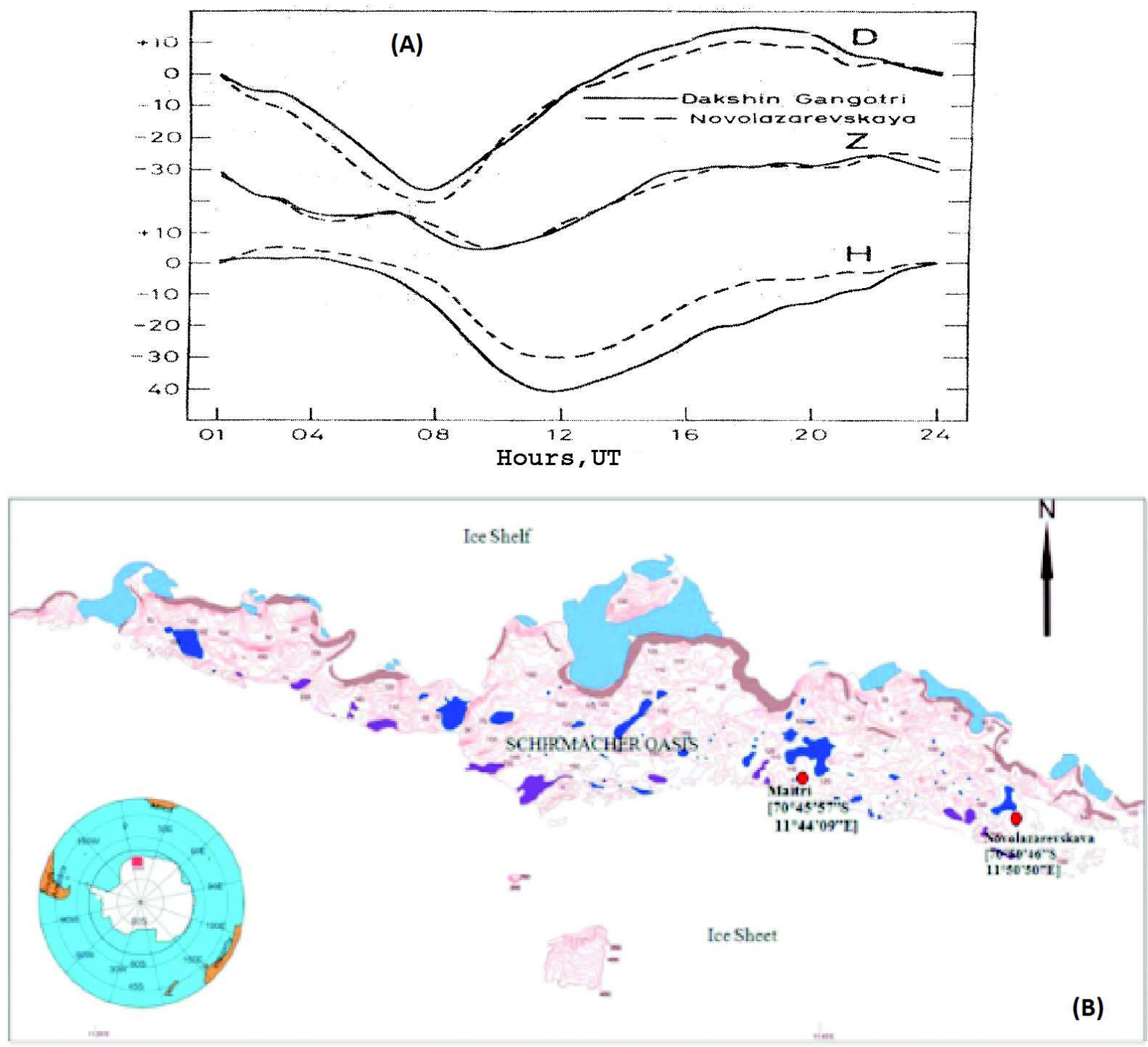

Fig. 1: (A) shows mean diurnal variations in $\mathrm{H}, \mathrm{Z}$ and $\mathrm{D}$ derived from records on quiet days at Dakshin Gangotri and Novolazarevskaya. (B) Shows geographic locations of Indian Antarctic station Maitri and Russian Antarctic station Novo in Schirmarcher Oasis. Though they are nearby stations, they do not exhibit identical geomagnetic variations 
dominant poles - Geographic, Dip and Corrected geomagnetic - are widely separated in Antarctic region, so that even two stations in close proximity geographically may show significant differences in the geomagnetic variations (Rangarajan and Dhar, 1988). The difference in geomagnetic variations between two geographically nearby stations is evident (Fig. 1 B).

The quiet-time $(\Sigma \mathrm{Kp} \leq 3)$ daily variations of the geomagnetic field at the Indian Antarctic station (refer Fig. 2), Maitri during two consecutive years of solar minimum was analyzed to investigate the characteristics of the solar quiet (Sq) current system and the signatures of the south limb of the Sq current loop of southern hemisphere over sub-auroral station. It was observed that Maitri behaves like a typical mid-latitude station during quiet magnetic conditions and seasonal variation of the Sq current strength over Maitri is strongest during summer months and weakest during winter months. In spite of the total darkness during winter months, Sq pattern is identified at Maitri.

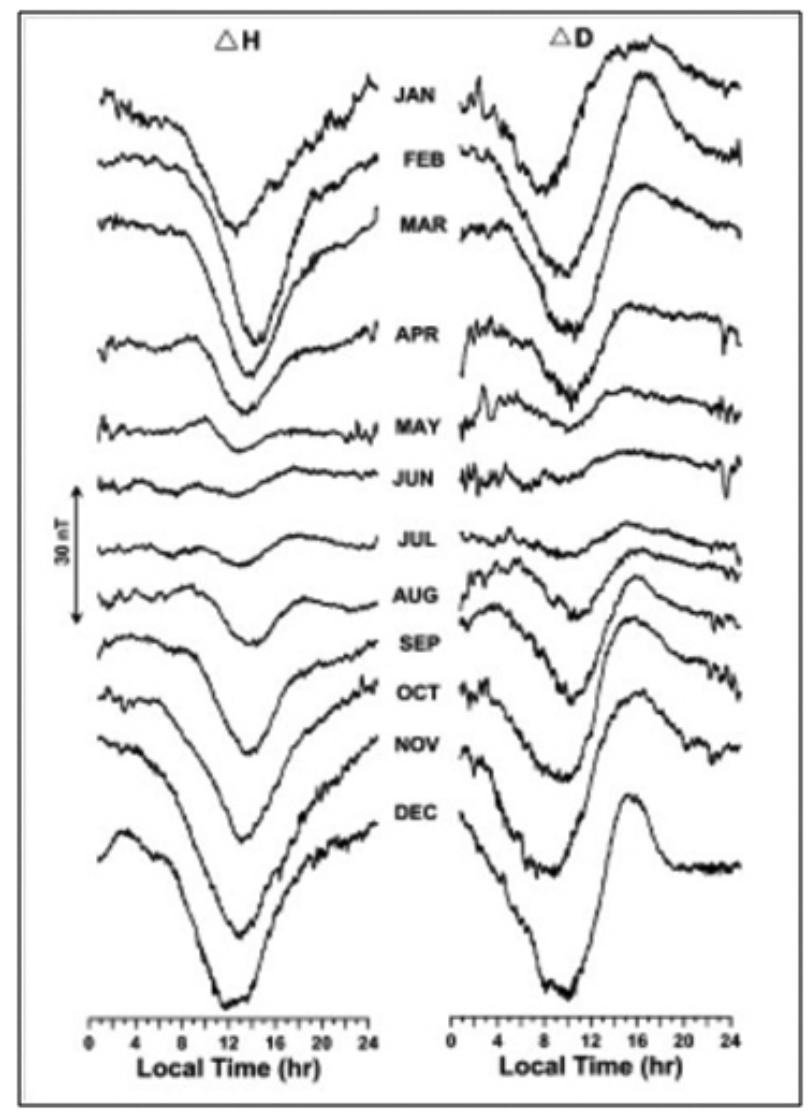

Fig. 2: $H$ - and $D$-variations during various months averaged over quiet days $\left(\_K p \geq 3\right)$ of years 2009 and 2010
The range of horizontal field variation in the daily Sq pattern during summer is one order higher than that during winter. A sharp shift in the time of peak Sq current to later local times ( $>1$ hour per month) is observed during Jan-Feb and July-August, which may correspond to the transactions from complete presence or absence of sunlight to partial sunlight. The differences in the incoming solar UV radiation during such transactions can cause a sudden change in the local ionospheric conductivity pattern, and can also trigger some unusual thermo-tidal activity, that might be responsible for modifying the global Sq pattern (Vichare et al., 2012).

\section{Geomagnetic Variations at Maitri in Relation to Space Weather}

The auroral oval regions are dynamic in nature and they can shift polewards or equatorwards, depending on the degree of electromagnetic disturbance in geospace. With change in geospace disturbance, the sub-auroral locations are ideal to sense the rapid changes in space weather. DG and Maitri occupy such an important location and shift in and out of auroral oval with increasing magnetic disturbance (Banola et al., 1997). During quiet magnetic conditions, Maitri is situated to the north of auroral oval and is influenced by southern limb of Sq current system. With increasing charge particle precipitation in auroral oval, the auroral oval expands and overlaps the station. During such conditions, Maitri is influenced by auroral electrojet and behaves like a typical auroral zone station. Thus, Maitri becomes an ideal location for 'Space Weather' studies. "Weather in Space" refers to degree of electromagnetic disturbance in the Earth's Space Environment (Geomagnetosphere). The auroral regions of the Earth serve as ideal locations for the remote sensing of Space Weather. These regions map to Central Plasma Sheet (CPS) region of the magnetosphere. The CPS represents the region of magnetosphere where large amount of Solar-Terrestrial energy exchange takes place, and this energy ultimately finds its way into the auroral ovals of the Earth. Thus the magnetic variation recorded on ground in auroral regions provides clues to physical processes in the distant magnetosphere, and hence to those in the Interplanetary medium and on the Sun.

The past two decades of experimental 
Geomagnetism at the Indian Antarctic station Maitri, using Magnetometer, Riometer, and observations of Optical aurora, has led us to the following conclusion:

Maitri is ideally suited for nowcasting Geospace Weather, and perhaps the Interplanetary Weather. The former refers to the degree of disturbance in electric and magnetic fields, and particle population in various regimes of the Earth's magnetosphere. The latter refers to the magnitude and direction of the solar
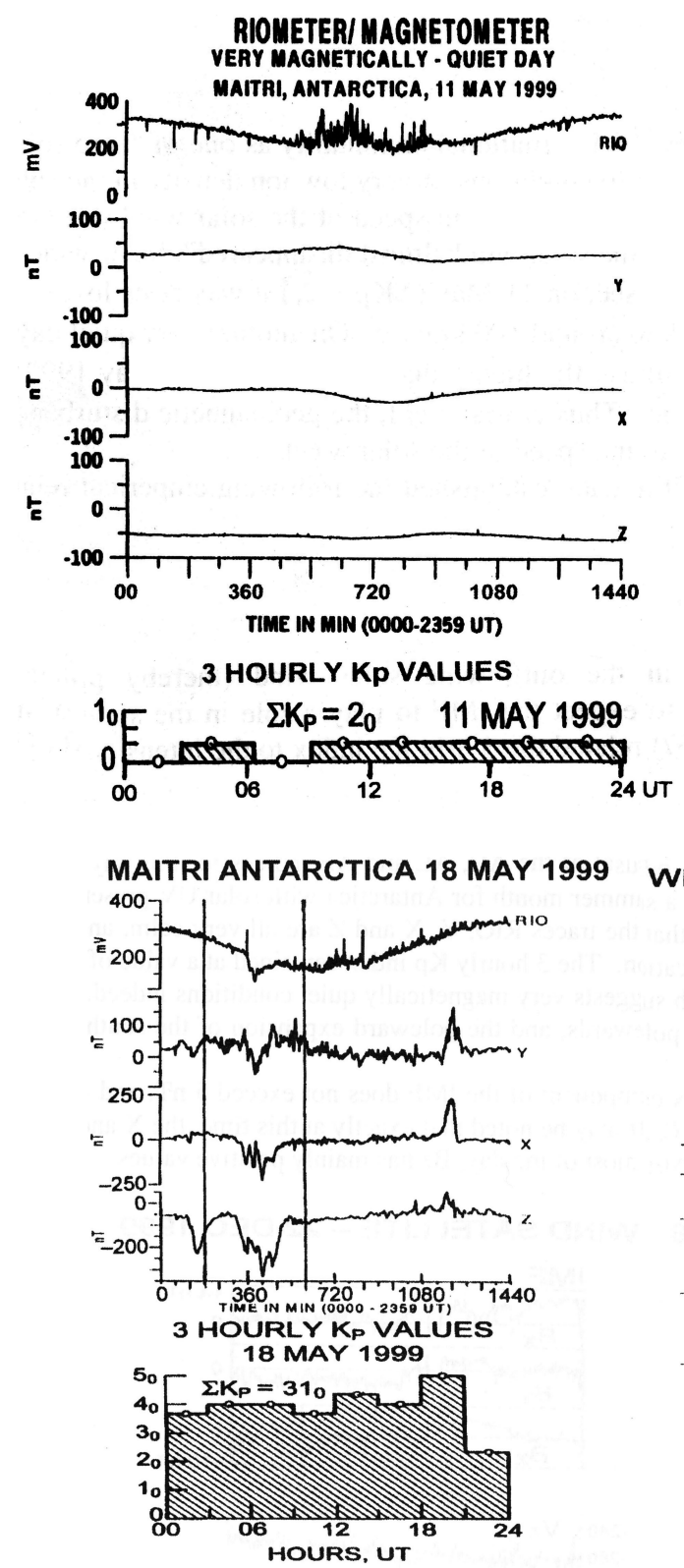

magnetic field components, and the velocity, density and dynamic pressure of solar wind particles in interplanetary space.

Comparison of $\mathrm{Y}, \mathrm{X}$ and $\mathrm{Z}$ variations and the Riometer absorption patterns at Maitri with the IMF variations and the interplanetary solar wind parameters measured by the WIND Satellite during 1999 (Fig. 3) show good agreement between the magnetometer and the Riometer variations and the southward component

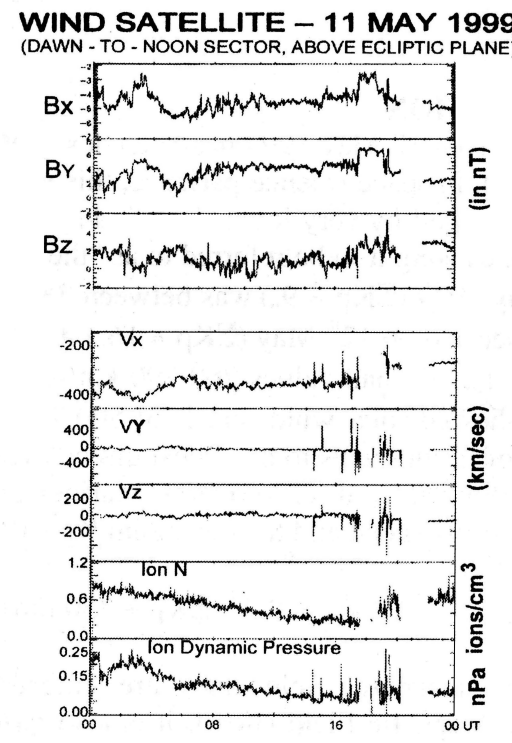

Fig. 3: (A) $30 \mathrm{MHz}$ Riometer and geomagnetic Y, X and Z variations at Maitri for the disturbed day of 11 May 1999 . Below is three hourly Kp values. The day the solar wind almost disappeared. IMF parameters for the same periods are shown on the right hand side for the comparison; (B) $30 \mathrm{MHz}$ Riometer and geomagnetic $\mathrm{Y}$, $\mathrm{X}$ and $\mathrm{Z}$ variations at Maitri for the disturbed day of 11 May 1999. Below is three hourly Kp values. The day the solar wind almost disappeared. IMF parameters for the same periods are shown on the right hand side for the comparison 
of the IMF, its intensity, the speed of the solar wind, and the ion dynamic pressure of the solar wind. The changes recorded by a fluxgate magnetometer and a $30 \mathrm{MHz}$ Riometer operating at Maitri during a splendid display of "aurora australis" on 4/5 March 1999 were interpreted in terms of currently - understood auroral physics. Interplanetary magnetic field and plasma parameters (Fig. 4) recorded by the WIND Satellite indicate very high solar wind velocities $(>600 \mathrm{~km} / \mathrm{sec})$, and prolonged southward $\mathrm{Bz}$ of average value $(<5$ $\mathrm{nT}$ ), during the auroral event. Ion density is however on an average $3-4 / \mathrm{cm}^{3}$, and ion pressure only 2-3 nano Pascals during the event (Rajaram et al., 2002).

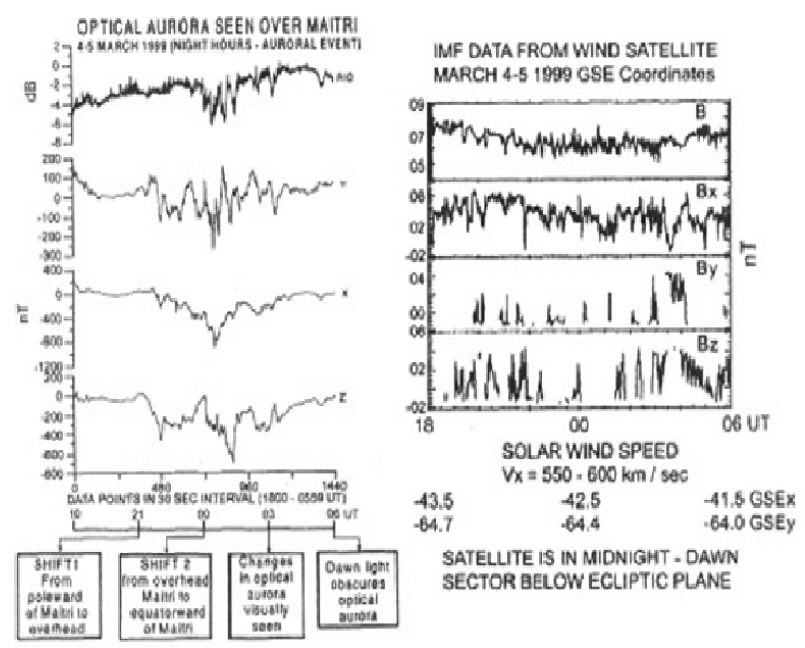

Fig. 4: Shift and change in the movement of optical aurora over Maitri and its ground geomagnetic signature from March 4, 18 UT to March 5, 06 UT 1999. Variations in IMF parameters are shown on right hand side for the same period

\section{Observation from Conjugate Stations}

Maitri does not have a conjugate location in the northern hemisphere as the field line originating from Maitri falls into Ocean (Fig. 5). In the absence of conjugate location for Maitri, magnetic data from Maitri was analyzed in corroboration with northern hemispheric two nearby stations LEIRVOGUR and NARSARSSUAQ, which fall on either side of the conjugate location of Maitri. LEIRVOGUR and NARSARSSUAQ are auroral zone stations and show the variations reflected by auroral electrojet and thus differed from the signatures recorded by Maitri during quiet magnetic conditions. During disturbed conditions, the variations however matched. This further confirmed the location of Maitri as sub-auroral (Dhar et al., 1993: Kalra et al., 1995).

\section{Triangular Magnetometer Experiment Around Maitri}

Magnetometers were operated at stations located at the vertices of a triangle around Maitri, with sides of $100-250 \mathrm{~km}$ to determine the presence and velocity of mobile, small-scale, auroral current systems over Maitri (Fig. 6). These currents while flowing over Maitri and surroundings, leave signatures over the ground based magnetometers. The velocities were determined from the time lags in these pulsations, The velocities of these mobile auroral current systems lie typically between 0.5 and $3.0 \mathrm{~km} / \mathrm{sec}$, and they tally well with the velocities obtained by various experimental groups in the northern auroral oval. During a particularly disturbed period of 28-31 Jan 1996 , very large drift speeds of 3 to $18 \mathrm{~km} / \mathrm{sec}$ were obtained from the time lags at the 3 stations, and this could be due to the presence of the eastward drifting Omega bands and westward traveling surges (Kalra et al., 1998; Dhar et al., 1999).

\section{Rapid Declining of Geomagnetic Field at and Around Maitri}

The dynamo process in the interior of the Earth generates a magnetic field that stretches up to the surface and beyond. The surface measurements of the geomagnetic field arise due to the internal field, however up to $10 \%$ contribution could be as a result of the ionospheric and magnetopsheric currents which are mainly controlled by the solar activity. The external currents vary at a much shorter scale (seconds to years) than the currents in the interior of the Earth. The long term variation in the geomagnetic field, arising due to the changes in the internal currents, is called as secular variation. The global secular variation suggests declining geomagnetic field intensity (Glatzmaier and Roberts, 1995; Pathan et al., 2009). The maximum rate of decline has been observed in the south Atlantic region. The Total Geomagnetic Field Intensity $\mathrm{F}$ measured at DG and later at Maitri, indicated a large drop between the year of 1987-1996 in the $F$ values. When compared with the values of $F$ for the geographic location of Maitri obtained from IGRF (International Geomagnetic Reference Field) for 1990, it showed a markedly decreasing trend for the years 1982, 1996, 1990 and 1996. Examination of the F values for 1922, 1951 and 1960 from earlier 


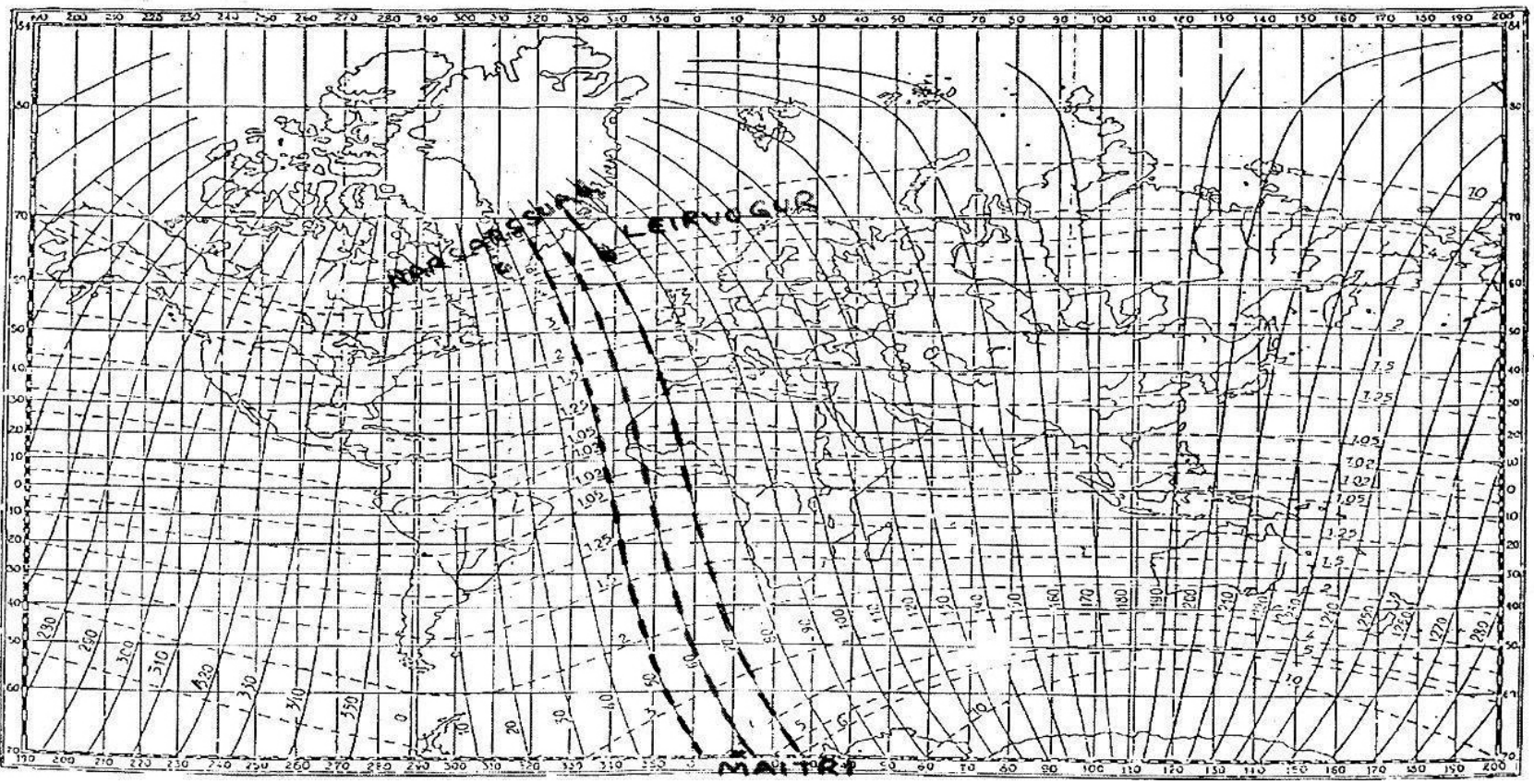

Fig. 5: In the absence of conjugate location for Maitri, magnetic data from two nearby stations LEIRVOGUR and NARSARSSUAQ was obtained and analyzed. These two stations fall on either side of the conjugate location of Maitri

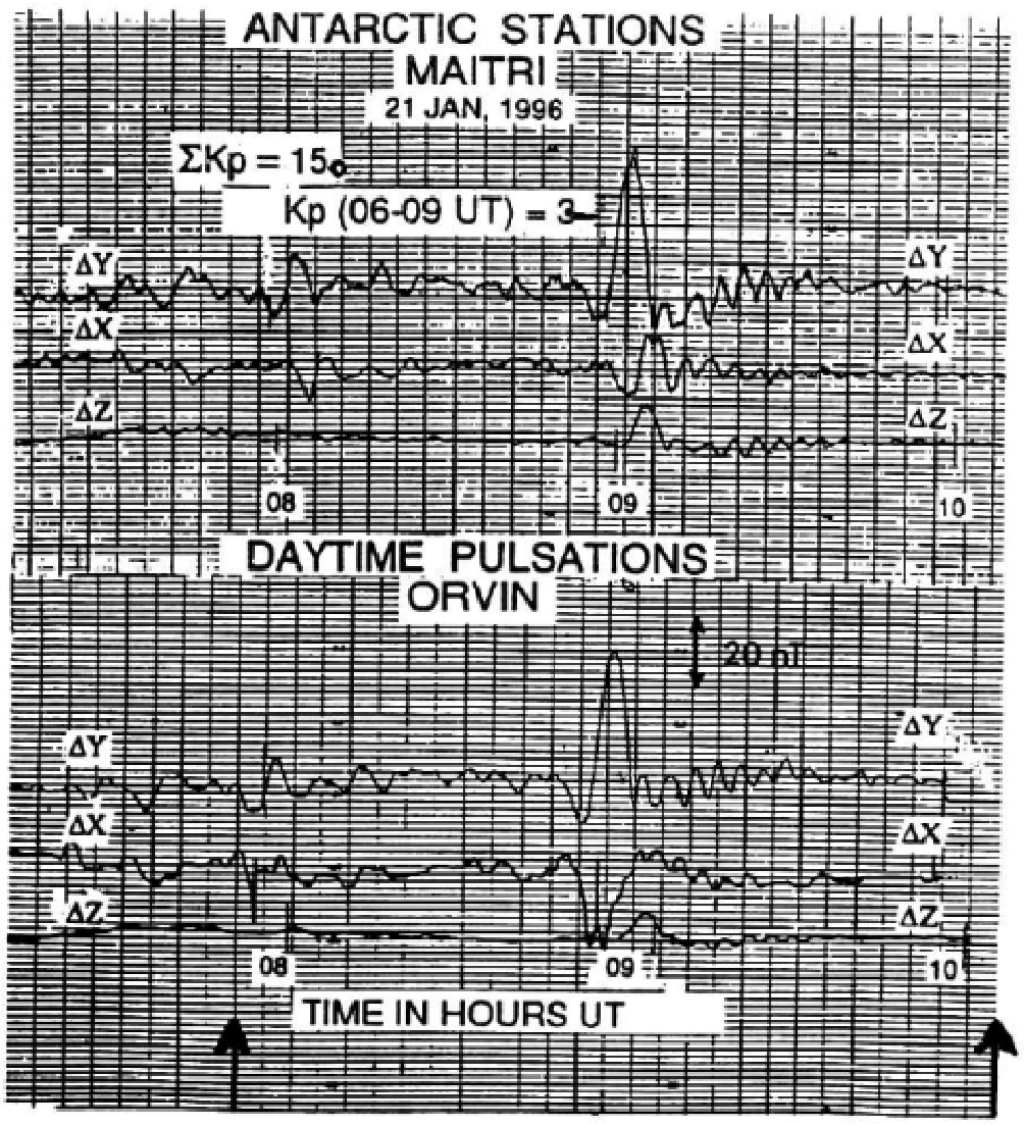

Fig. 6: Simultaneous geomagnetic pulsations at two locations MAITRI and ORVIN on 21 Jan 1996 between 0800 and 1000 UT. The drift speed of the small scale ionospheric current systems are estimated from the time lag in similar pulsations
Magnetic Charts for this location, the resulting curve suggested a drop of about $8000 \mathrm{nT}$ in the past 75 years. A decrease of nearly $17 \%$ was observed since 1922 , which is a considerable magnitude within 75 years (Arun et al., 2000; Rajaram et al., 2002; Pathan et al., 2009). Recent observations of the magnetic field intensity at Maitri suggest annual decline rate has dropped about $60 \mathrm{nT} /$ year, which is consistent with international geomagnetic reference field (IGRF) model (see Fig. 7).

An examination of total magmatic field (F) data from other stations (Figs. 8 and 9) in the northern and southern hemisphere suggested that this decrease was occurring only in the southern hemisphere. Bormann et al. (1995) had reported a decrease of about $100 \mathrm{nT} / \mathrm{yr}$ at Novolazarevskaya (Russian) and George Foster (German) stations, both the stations located in the vicinity of Maitri. The rate of decrease observed at southern hemisphere high latitude stations is as follows: 


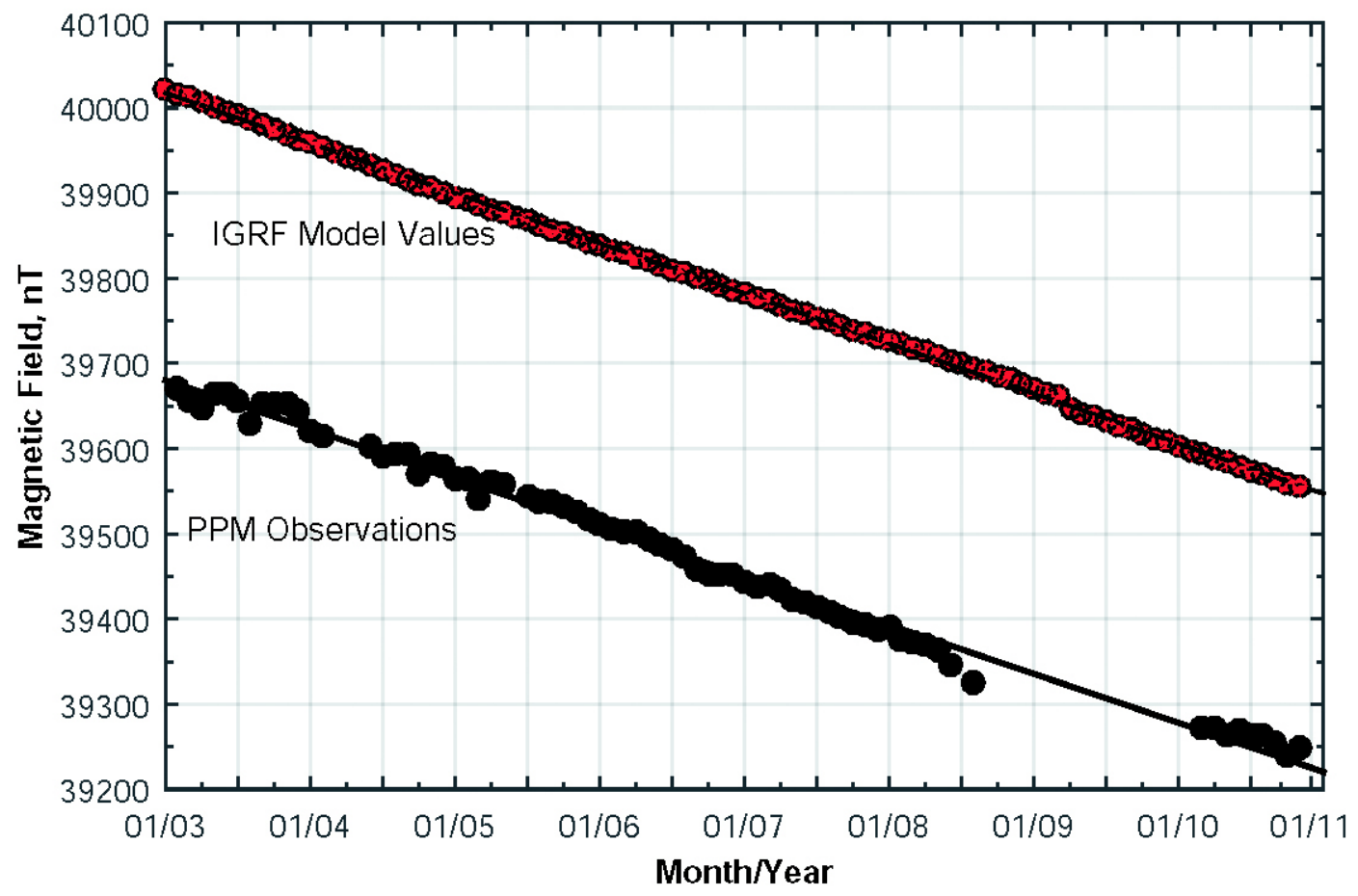

Fig. 7: Observed and modeled intensity of geomagnetic field at Maitri during years 2003-2010 show annual decline of about 60 nT/year

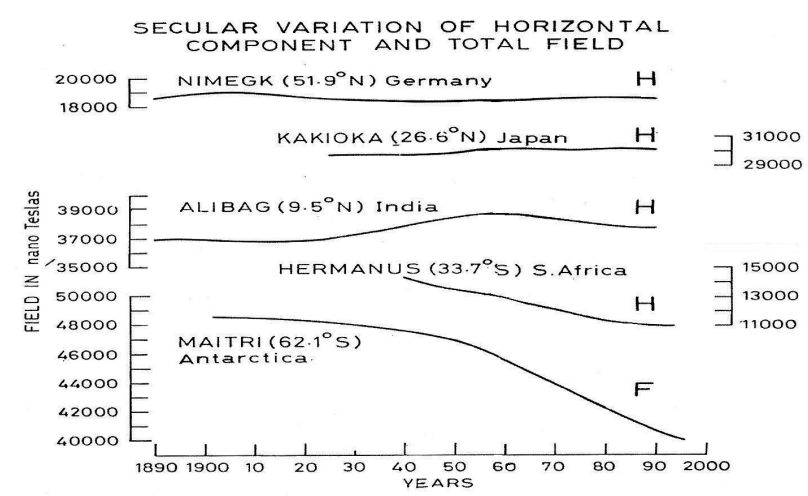

Fig. 8: Variation of the principal component of the geomagnetic field over the past century (1890-1996 A.D.) at northern hemisphere stations (Nemegk, Kakioka and Alibag) and at southern hemisphere stations (Harmanus and Maitri)

Novolazarevskaya: 108 nT/yr, Sanae: 108 nT/yr, Hermanus: 105 nT/yr, Argentine Island: 103 nT/yr, Syowa: 94 nT/yr, Halley Bay: 91 nT/yr, Davis: 73 nT/ yr, Mawson: 72 nT/yr, Dumont d'Urville: 50 nT/yr (Rajaram et al., 2002).

Further analysis of magnetic data from highlatitude stations in northern and southern stations indicated that this rapid decline is confined to a narrow
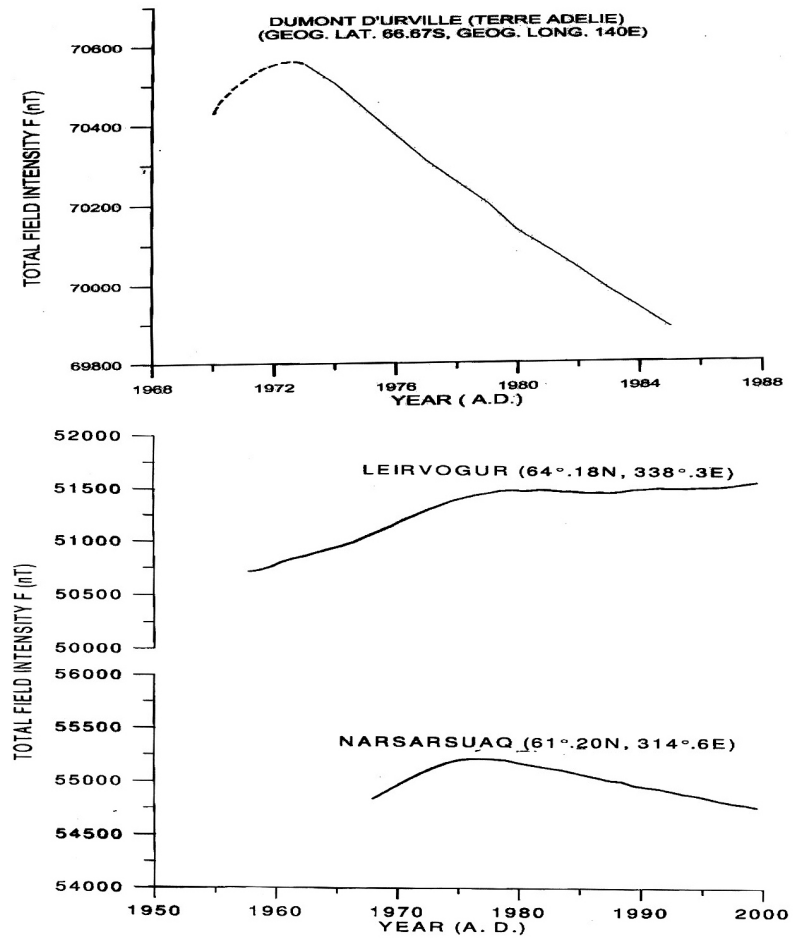

Fig. 9: GeomagneticTotal Field $(F)$ variation at two northern hemisphere stations Narsarssuaq, Leirvogur and southern hemisphere station Demont D' Durville

horse shoe shaped belt in the Antarctic region, encompassing Maitri (Arun et al., 2000). The rate of 
decline falls as one moves away in the poleward or equatorward direction. Gubbins (1988), defined these areas as 'Regions of Reverse Magnetic Flux'. Continuous monitoring of the $\mathrm{F}$ values as well as the efforts to modeling the decline will be useful in future. The Fig. 10 shows the contours of rate of average decrease in $\mathrm{F}$ (nT/yr) over the past five decades (19501999) for Antarctic and sub-Antarctic stations between $30^{\circ}-90^{\circ} \mathrm{S}$ in geographic and geomagnetic coordinates. The locations of the stations considered are shown using star symbols.

\section{Substorm Dynamics at Maitri and Bharati Stations in Antarctica}

Continuously emanating charged particles from the Sun expand into the interplanetary space. The earthward directed stream of the solar wind confines the earth's magnetic field in a cavity like shape called as "magnetosphere". The dayside magnetosphere expends to about 8-10 $R_{E}$ (where $R_{E}$ is the radius of the Earth) on the dayside whereas it stretches beyond several 100s of $R_{E}$ on the nightside in the form of a long tail known as "magnetotail". A fraction of the solar wind plasma and energy is stored in the Earth's magnetotail through magnetic reconnection process and ultimately released into the inner magnetosphere across the geomagnetic field lines and additionally diverted along the field lines to the polar regions during a process called as "substorm". Substorms manifest in the form for spectacular auroral displays, intense magnetic field variations, etc. (Rostoker et al., 1980; Kellerman and Makarevich, 2011; Singh et al., 2012; Murphy et al., 2014). During intense events, precipitation of energetic charged particles into the polar atmosphere leads to enhanced cosmic radio noise absorption (Behera et al., 2015), which influences the dynamics of the neutral atmosphere (Codrescu et al., 1997) and even possibly the surface air temperature (Seppälä et al., 2009). In addition to variations with local time, latitude and season, substorm characteristics vary over the solar cycle due to dominance of different solar wind drivers (Tanskanen, 2009; Tsurutani et al., 2015).

Auroral latitudes (magnetic $60^{\circ}-70^{\circ}$ ) are the most severely affected region due to substorm activity. Nevertheless, nearly all regions including the low latitudes undergo significant magnetic and electric field changes during substorms (McPherron et al., 1973; Singh et al., 2011). During the course of a substorm, extremely intense currents of the order of $10^{6}$ A flow into the auroral ionosphere (Kamide and Kokubun, 1996), which can be easily monitored using satellite and ground based magnetometers. As a result of the short-lived, extremely intense auroral electrojets, the geomagnetic field could vary up to $10 \%$ of its total value. The direction and intensity of
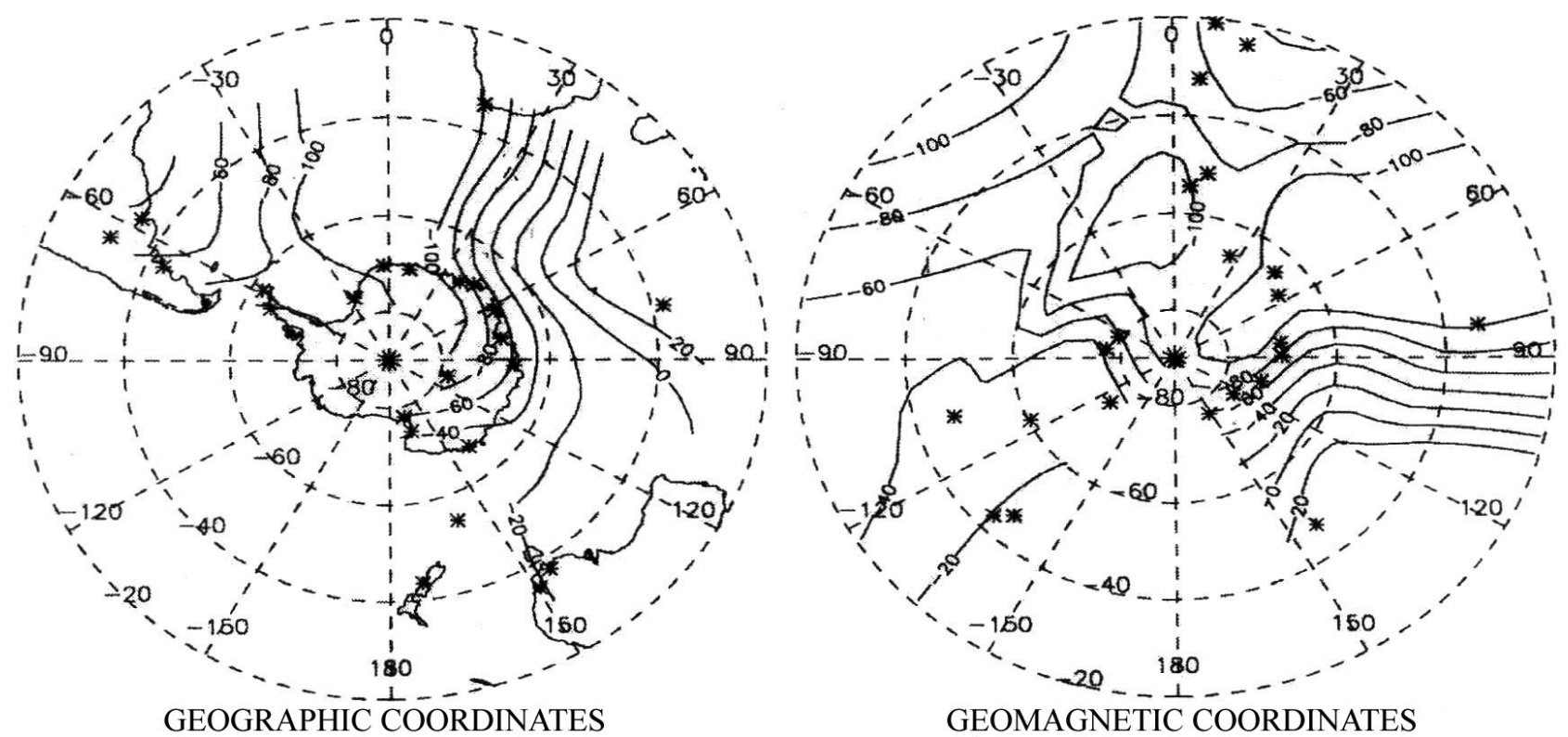

Fig. 10: Conditions of total magnetic field $F$ variation in $n T / y r$ for the period 1950-2000 AD, using data from stations located in the $30-90^{\circ} \mathrm{S}$ latitude region 
the auroral electrojets mainly depend on the local times, for example, eastward current adds to the ambient geomagnetic field and is typically observed near dusk hours whereas westward current leads to a sharp depression near the local midnight (Rostoker et al., 1980). The intensification of the westward auroral electrojet is believed to be more closely related to the onset substorm.

Disturbances in the horizontal $(\mathrm{H})$ components, observed at selected 10-12 longitudinally distributed auroral observatories in the northern hemisphere, have been used over several decades to derive auroral electrojet (AE) indices to monitor substorms (Davis and Sugiura, 1966). The auroral oval is often confined between $60^{\circ}-70^{\circ}$ magnetic latitude, however it expands equatorward and contracts poleward in accordance with changes in IMF, solar wind pressure variations and level of geomagnetic activity (Kamide and Akasofu, 1983). Moreover, there could be significant hemispherical asymmetry in the substorm characteristics (Newell et al., 2010; Singh et al., 2012).

Indian research bases - Maitri and Bharati in Antarctica (respectively at magnetic latitude $63^{\circ} \mathrm{S}$ and $75^{\circ} \mathrm{S}$ ) are suitably located near the boundaries of the most dynamic auroral oval in the southern hemisphere.
Years-long magnetic field observations in corroboration with other relevant data sets have been extensively used for the better insight of the substorm process and subsequent energy input into the upper atmosphere.

Morphology of Auroral Electrojets at Maitri Station: The local H, D and $\mathrm{Z}$ magnetic variations are generally sensitive to the east-west currents, fieldaligned current and spatial gradient of the zonal (eastwest) currents, respectively. Typical magnetic field components variation under the influence of the eastward and westward currents prevailing at different local times at Maitri are demonstrated in Fig. 11. It was inferred from the in-phase $\mathrm{H}$ and $\mathrm{Z}$ variations for the events that Maitri station being near the equatorward boundary of the auroral oval, the center of the eastward as well as westward electrojet for the events shown in Fig. 11 was poleward of our station (see Singh et al., 2012).

Identification of auroral electrojet onset over the years 2003-2008 was carried out using a customized automatic algorithm of Newell and Gjerloev (2011) (see Singh et al., 2016 for details). About 500 eastward electrojet events were identified whereas the number of events for the westward electrojet was about 3 times higher than the former. The auroral
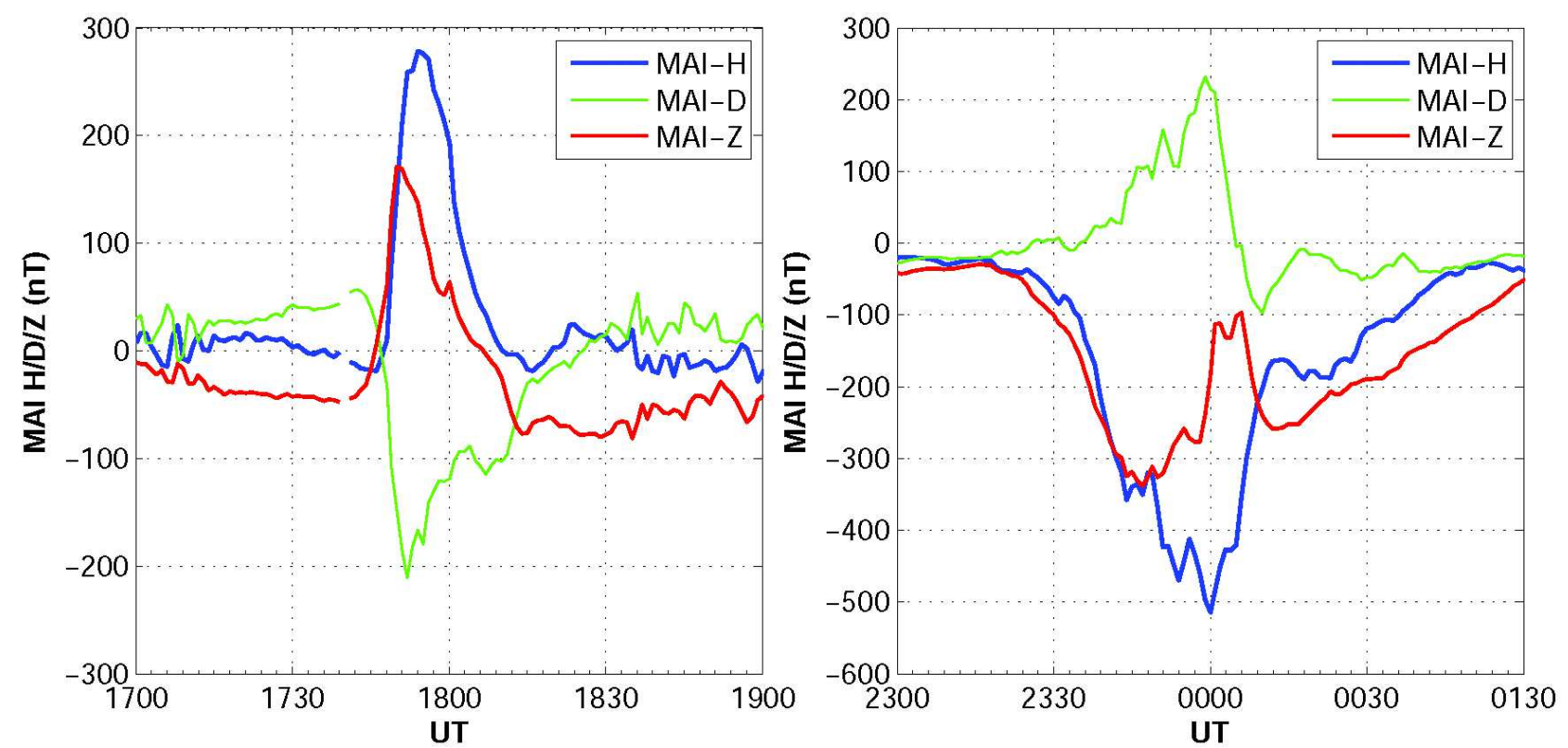

Fig. 11: Variations of the geomagnetic field components under the influence of eastward and westward auroral electrojets over Maitri. Positive H excursion (blue curve) represents dominance of eastward electrojet (left panel) whereas westward electrojet prevails around midnight (right panel) 
electrojets at Maitri were observed to have profound solar cycle and local time variations as shown in Figs. 12 and 13 . The yearly distribution of electrojet onsets have been shown in the Fig. 12. The thick red curve represents the yearly sunspot number. Occurrences of the auroral electrojets events varied in accordance with the solar activity as represented by the sunspot number, except for the year 2005 when several transient solar events were witnessed (Singh et al., 2015). During the deep solar minimum years 2007 and 2008 , the auroral electrojet activity fairly subsided. However, the eastward and westward electrojet occurrences do not change in the same proportion thereby suggesting the fact that the drivers for the

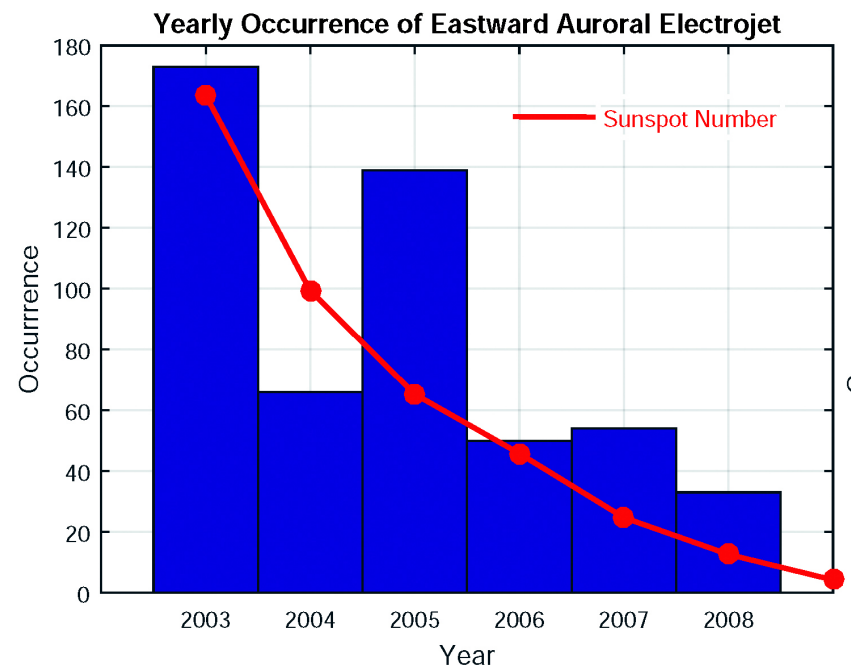

two auroral electrojets are not essentially same (Kamide and Rostoker, 2004).

The local time and magnetic local time are almost same as the universal time (UT) for Maitri station. Occurrence of the eastward electrojet maximizes around dusk hours $(1800 \mathrm{~h})$ whereas the westward electrojet peaks around midnight $(0000 \mathrm{~h})$ (please refer Fig. 13). However, there are notable differences in the local time distribution of the two electrojets, viz. the eastward electrojet regime spreads to a broader local time than the westward electrojet. The probability of occurrence of the eastward electrojet appears similar on either side of the dusk $(1800 \mathrm{~h})$ as shown in the left panel of Fig. 13, whereas for the westward

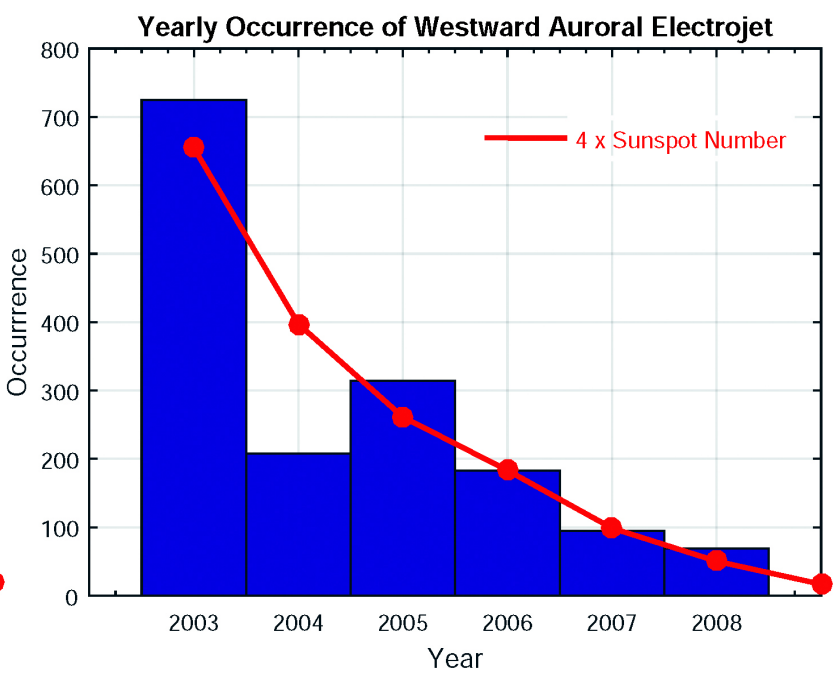

Fig. 12: Yearly occurrences of the eastward (left panel) and westward (right panel) auroral electojets over Maitri during years 2003-2008. The sunspot number is shown by the red curve
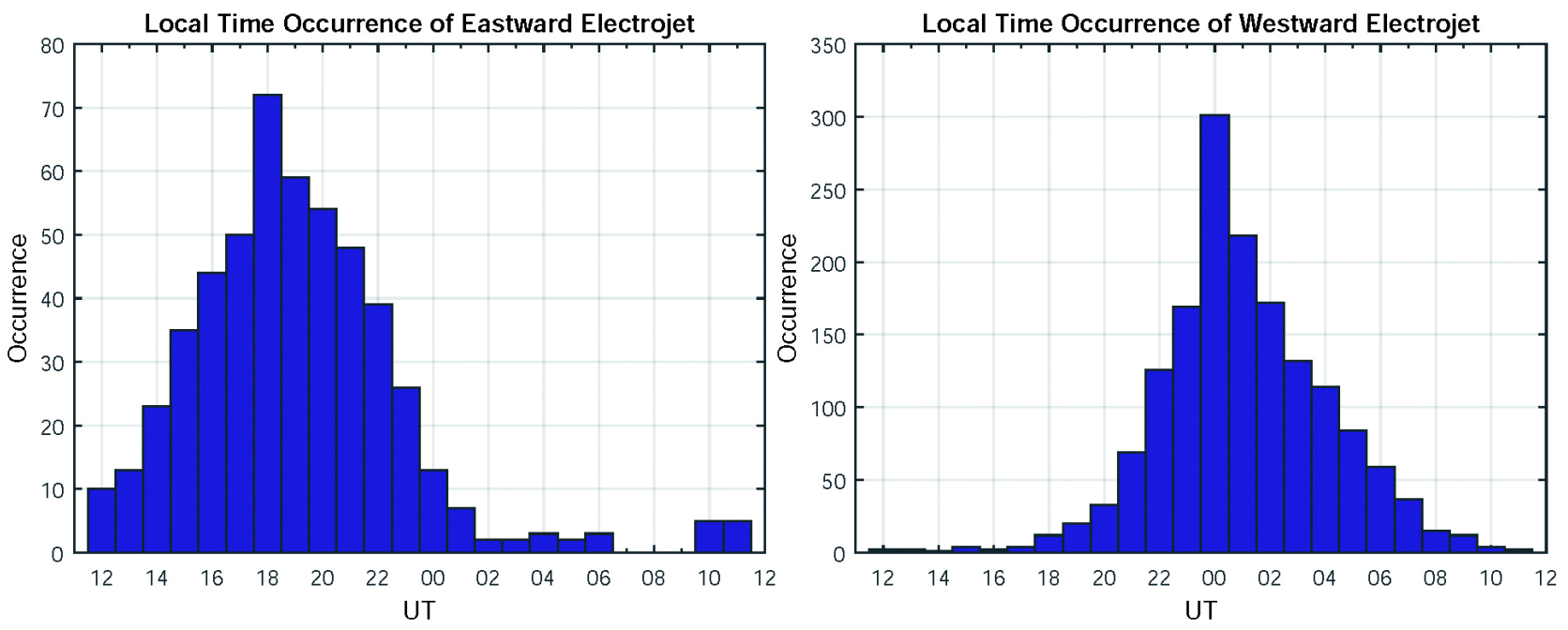

Fig. 13: Local time characteristics of the eastward and westward auroral electrojets at Maitri. The eastward electrojet maximizes around $1800 \mathrm{hrs}$ (left panel) and westward electrojet peaks around the midnight (right panel) 
electrojet the probability of occurrence is higher towards post-midnight than those occurring in the premidnight.

Substorm Dynamics at Very High Latitudes: Prolonged quiet geomagnetic conditions lead to the initiation of substorms at unusually high latitudes, which may go unnoticed at the standard auroral latitudes or in the $\mathrm{AE}$ indices. Bharati station $\left(\sim 75^{\circ}\right.$ magnetic latitude) is ideally located for observing such events. A typical event occurred on 02 March 2008 as shown in Fig. 14 when the substorm was localized at very high latitudes. The substorm signature was observed in both the hemispheres. Hornsund station (geographic location $77.0^{\circ} \mathrm{N} 15.6^{\circ} \mathrm{E}$ ) forms a near conjugate pair with Bharati. A depression of about $500 \mathrm{nT}$ was observed at Bharati and Hornsund in relation to the substorm event. No appreciable disturbance was observed at the standard auroral latitudes, nevertheless the substorm current wedge produced asymmetric magnetic field at the low latitudes (bottom panel of Fig. 14).

Analysis of about 100 days of magnetic data collected during years 2007-2010 in campaign mode at Bharati station suggested that the very high latitude substorms predominantly occur around midnight hours in a way similar to usual substorms (Fig. 15a). Majority of substorms were observed during the slow to moderate solar wind conditions (Fig. 15b) in contrast to the previous studies (Papitashvili et al., 2002). Magnetic signatures of very high latitude substorms often observed were more pronounced in the winter hemisphere (at Hornsund station) than those observed in the summer hemisphere as shown in Fig. 15c. This could probably be due to differences in the ionospheric conductivities due to differential solar illumination.

\section{Charged Particle Precipitation During Geomagnetic Disturbances}

Precipitation of charged particles, especially electrons into the auroral latitudes during substorm activity and associated transient changes in high latitude ionosphere are also the important aspects of space weather research. Precipitation phenomena are even more significant as they link to Van allen radiation belts and Earth's atmosphere. Study of the precipitation process has recently got immense attention from the space and climate research point of view. Not only will it help us to understand dynamics of the radiation belts and related energetic electron flux evolution but also may provide a viable mechanism to explain the link between the atmospheric precipitation of solar energetic particles and polar climate Variability (S. Kirkwood et al., 2015; Rodger et al., 2013; Turunen et al., 2009; Seppala et al., 2007).

For many decades, Cosmic Noise Absorption (CNA) phenomena is possibly considered as the low

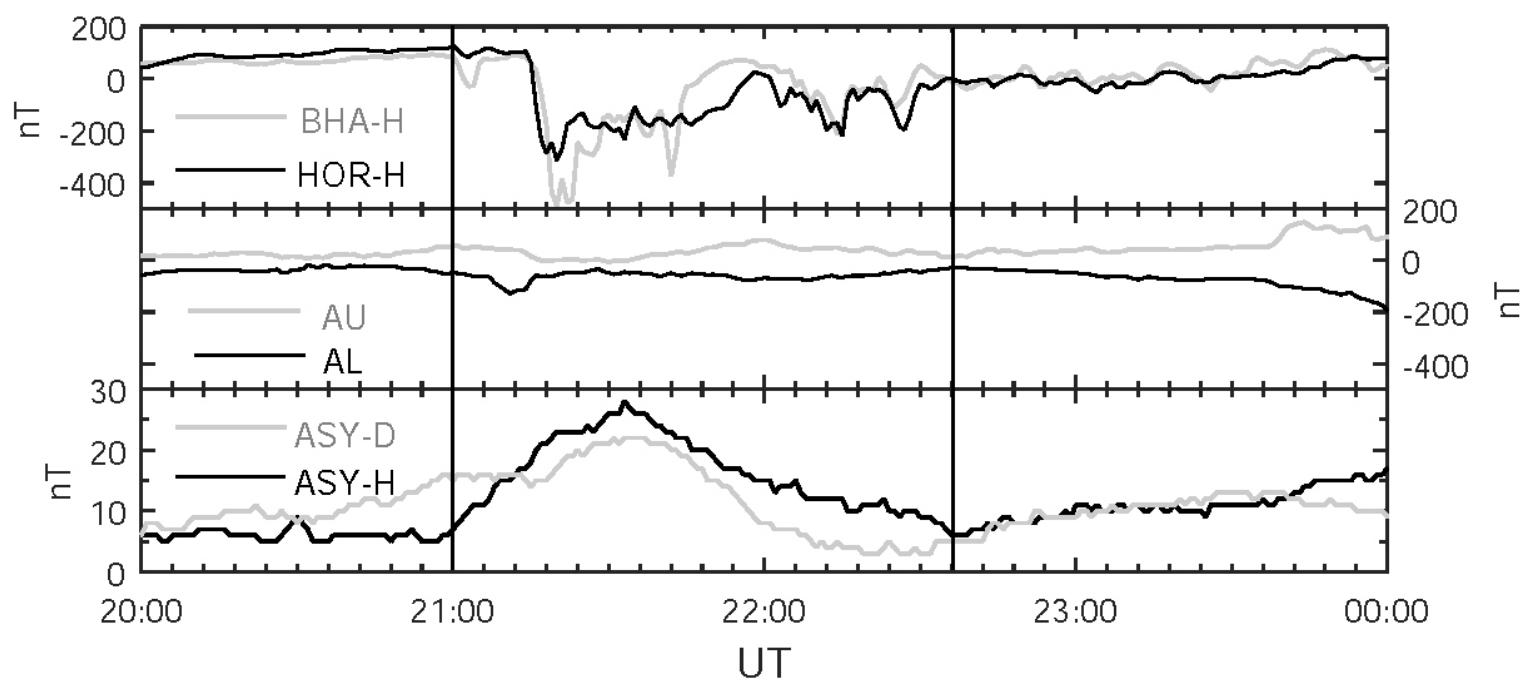

Fig. 14: Very high latitude substorm on 02 March 2008 leading to a depression of about 500 nT at Bharati and Hornsund station in the northern hemisphere (Fig.ure adapted from Singh et al., 2012). No appreciable magnetic field variation was observed at the auroral latitude (middle panel), however noticeable asymmetry at the low latitude was evident (bottom panel) 
(A)
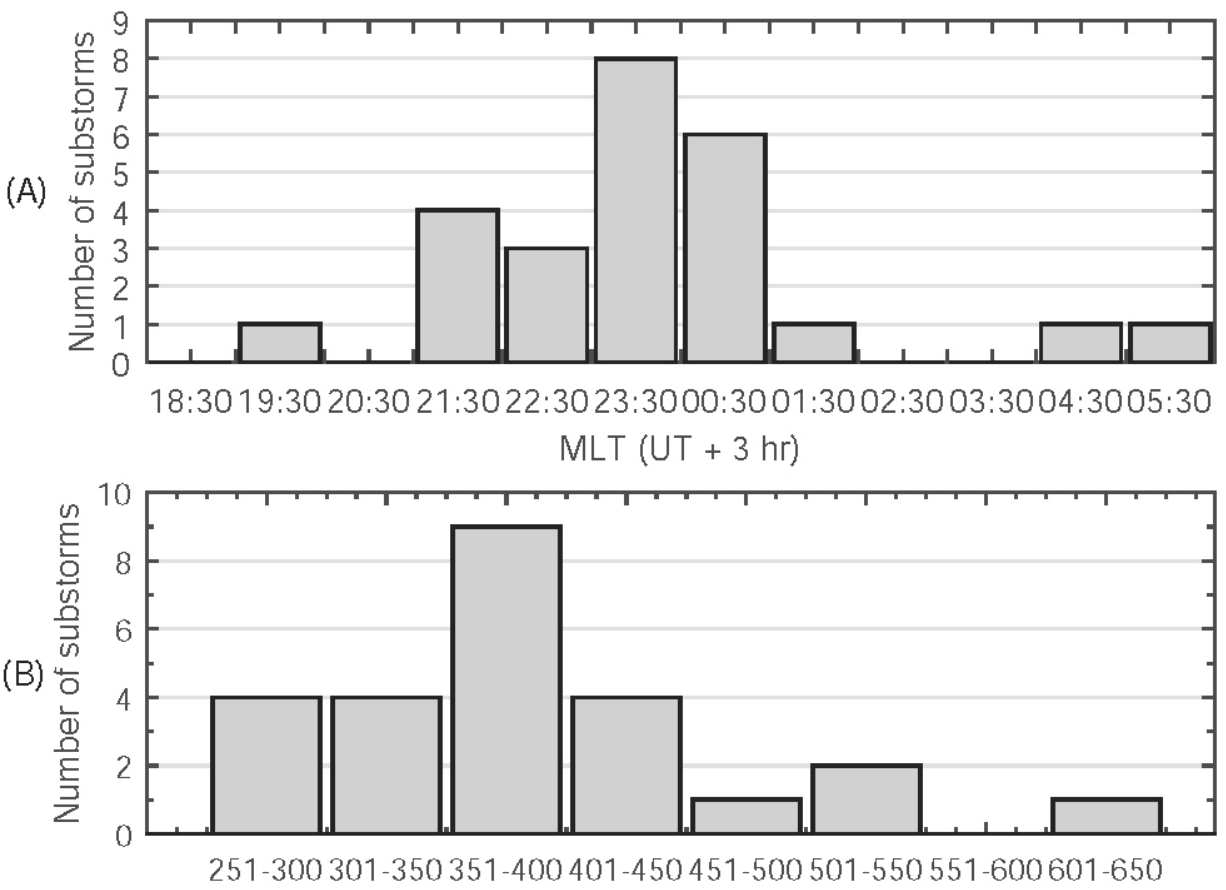

$\mathrm{V}_{\mathrm{SW}}(\mathrm{km} / \mathrm{s})$

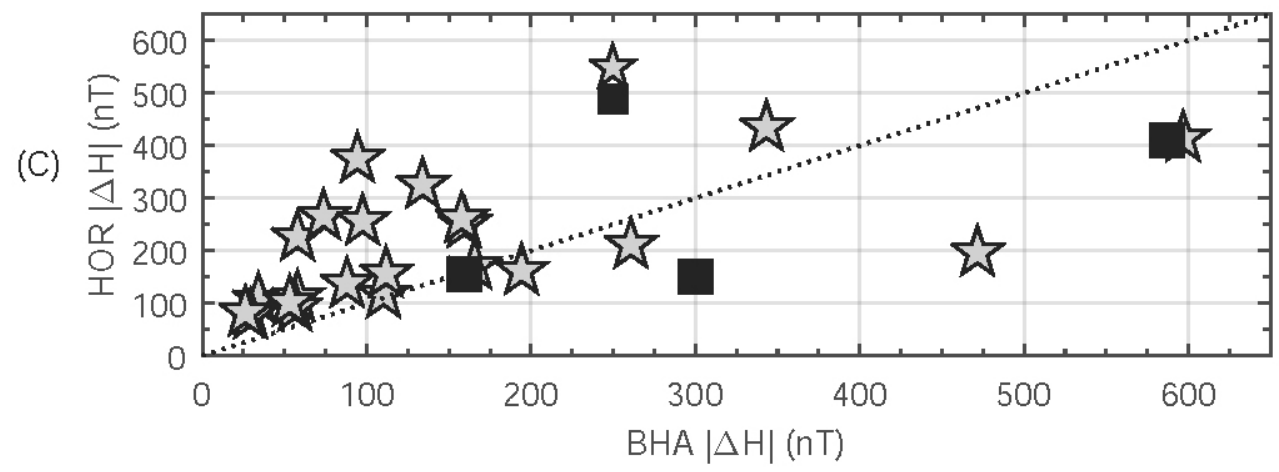

Fig. 15: Characteristics of very high latitude substorms observed over Bharati: (A) Occurrence in local time (B) dependence with speed of solar wind and (C) hemispherical asymmetry in the intensity of substorm. (Adapted from Singh et al., 2012)

cost and handy proxy to decipher the energetic particle precipitation at high latitude Ionosphere, mostly in Dregion (Little and Leinbach, 1959). The process of deposition is either in the open field line region at the day side of magnetosphere or in the closed field line region in the night side (Newell and Meng, 1992). However, the night side precipitations is mainly due to high energetic electrons in the energy range of $(>20$ Kev) inside the auroral region (Hargreaves, 1969). Softer electrons ( $<10 \mathrm{Kev})$ are responsible for auroral display and in some part for intensification of auroral electrojet in ionospheric $\mathrm{E}$ and $\mathrm{F}$ regions. Harder electrons such as $30 \mathrm{KeV}$ to few $\mathrm{MeV}$ can penetrate deeper into the ionosphere and subsequently affect the composition of the middle atmosphere (Codrescu et al., 1997). Apparently, use of wide beam riometer for the particle precipitation could not provide the spatial information of the CNA pattern and later was replaced by advanced arrays of riometers forming different beams in 1990 and are called imaging Riometer (Detrick and Rosenberg, 1990).

First results from Imaging Riometer Installed at Maitri: An imaging Riometer (shown in Fig. 16) is installed at Indian Antarctic station Maitri (Geographic 70.75 degree S, 11.75 degree E; corrected geomagnetic 63.11 degree $S, 53.59$ degree E) in February 2010. Initial results from the imaging 


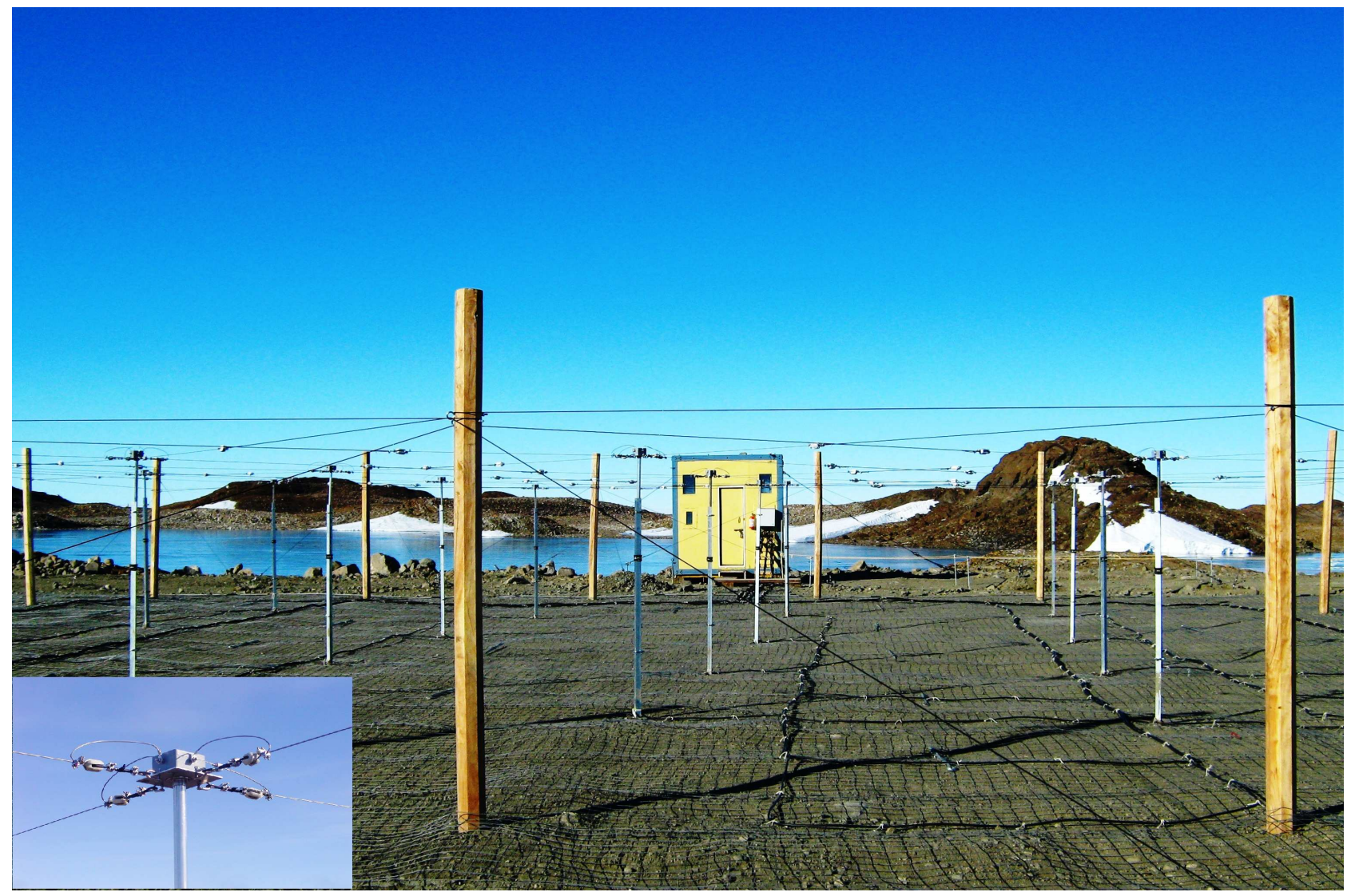

Fig. 16: South-east view of the installed imaging Riometer at Maitri. It includes the antenna and the hut (yellow color hut) where the reciever unit is kept

Riometer data shows Sidereal shift of around 2 hours in the diurnal pattern which validate its data (Please refer Fig. 17). Also, the variation in the strength of cosmic noise signal with months is observed. This is apparently due to solar ionization of D-region ionosphere causing enhanced electron density where collision frequency is already high. The main objective of installing the imaging Riometer at Maitri is to study Magneotspheric-Ionospheric coupling during substorm processes. Hence, many typical examples of disturbed time CNA associated with storm-time and non-storm time substorm have been analyzed. Results reveal that CNA is more pronounced during stormtime substorm as compared to non-storm time substorm or, isolated. Further, initial results confirm that the level of CNA strongly depends upon the strengthening of convection electric field and the duration of southward turning of interplanetary magnetic field before the substorm onset (Behera et al., 2014).

Characteristics of Auroral Substorm Event During Substorm: Precipitations of energetic charged particles during the course of a magnetospheric substorm simultaneously affect upper and lower regions of the ionosphere. However, this depends on the energy of the charged particle flux in particular. Many previous studies (FrankKamenetesky and Troshichev, 2011; Kavanagh et al., 2002; Staunning et al., 1996) have reported that intense and short-lived CNA events associated with substorms are mostly observed in the midnight sector of the auroral oval. We have examined such type of CNA events as shown in Fig. 18 predominantly occurring during 0000-0600 UT (2300-0500 MLT) at Indian Antarctic station Maitri (corrected geomagnetic $(\mathrm{CGM})$ coordinates $62.59^{0} \mathrm{~S}, 53.59^{0} \mathrm{E}$ ), which is located at the equator-ward edge of the auroral oval. Contrast to the earlier reports on the occurrences of auroral substorm absorption events, our study reveals that these kind of CNA's occur in the post midnight sector $(\sim 0200$ UT). Identification of these events was done based on some strict criteria. Further, statistical study of such events show that absorption events related to isolated substorm and storm-time 


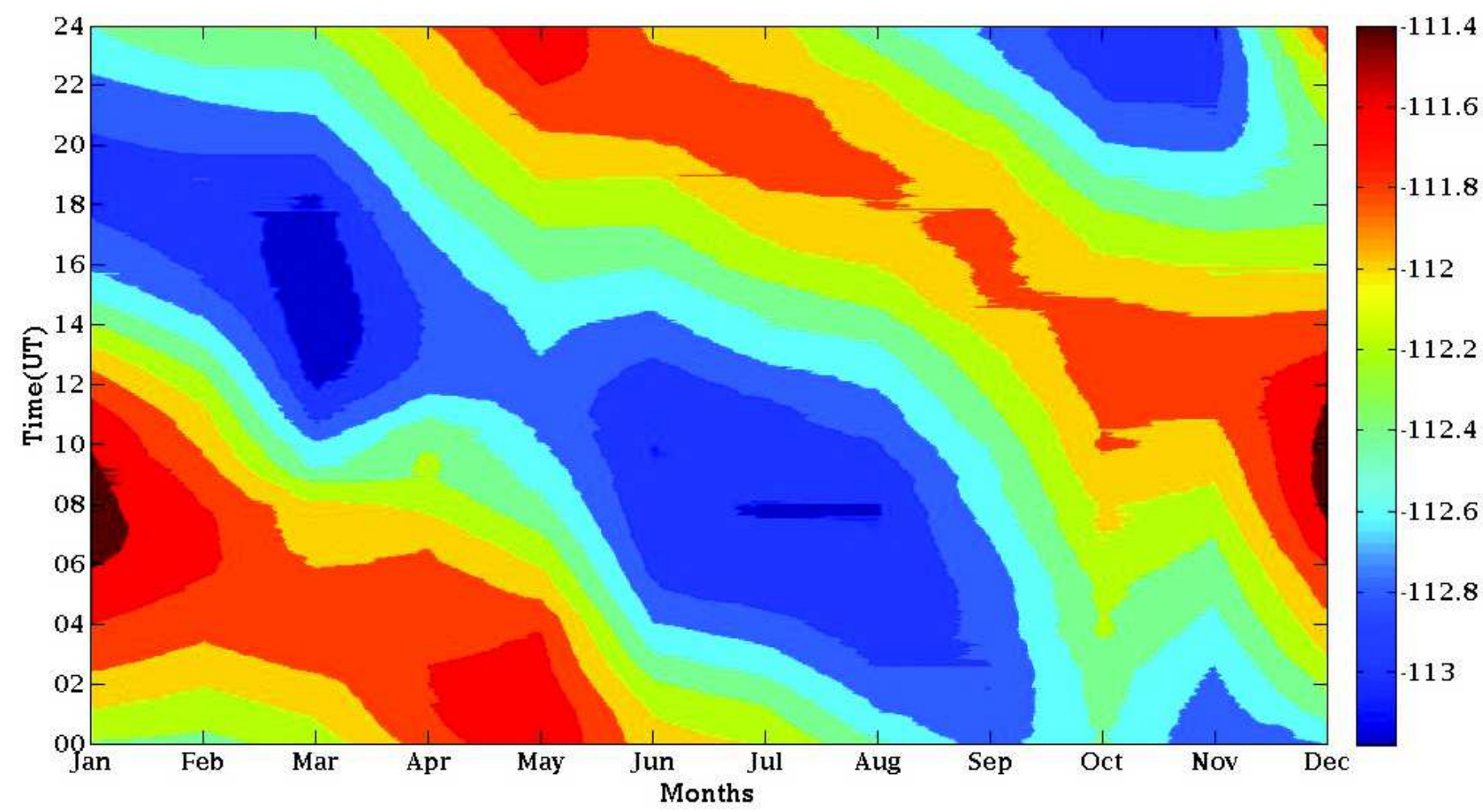

Fig. 17: Contour plot for Sidereal shift of maximum signal strength of Cosmic noise signal for consecutive months. For the month January to May, shift of $\sim 10$ hours ( 10 UT to 00 UT) of maximum signal strength is seen. Similarly, for the month June to December, shift of $\sim 14$ hours ( 24 UT to 10 UT) is seen

substorms exhibit distinct features in terms of their intensity and extent in latitude and longitude. Also, the statistical study suggests that the maximum intensity of CNA's depends on the interplanetary conditions as shown in Fig. 19, such as, the solar wind speed with correlation coefficient $(r)$ of 0.5 , southward component of IMF $B z(r=0.75)$, and duskward component of IEF Ey $(r=0.85)$. The comparison showed that role of duskward component of IEF Ey is found to be more noteworthy than other interplanetary parameters.

Day Side Cosmic Noise Absorption Event Due to Eastward Propagating Kev Electron Flux: On 02 April 2011, a couple of cosmic noise absorptions (CNA) events were detected at Maitri, Antarctica $\left(\mathrm{L}=5, \mathrm{CGM} 63.14^{0} \mathrm{~S}, 53.69^{\circ} \mathrm{E}\right)$ confining to night and day times as shown in Fig. 20. One of the two events that occurred during night hours was caused due to auroral substorm onset. Our interest immediately went on to the later CNA event, which was recorded during daytime (1000-1300 MLT, At Maitri, MLT= UT-1). We refer to this CNA event as day side CNA(DCNA) event. Absence of westward electrojet during DCNA confirmed its dissimilarity from Auroral Substorm absorption events. Further, a comparison has been made between the DCNA event of 02 April 2011 with that of 14 July 2011, a day with substorm activity when Maitri is in day side but without DCNA event (Behera et al., 2016). The comparison has been made in the light of interplanetary conditions, imaging Riometer data, ground magnetic signatures. Fig. 21 presents the GOES-13 satellite observation of electron fluxes with 40-475 KeV energy range showing clear enhancement during substorms on both the days (02 April, 2011 and 14 July, 2015) when Maitri was on the dayside. However, electron flux in the energy band of 150 and $275 \mathrm{KeV}$ during DCNA day have increased by more than 2 folds compared to the day of 14, July, 2011. Also, the study showed that stronger prolonged eastward interplanetary electric field favored the occurrence of DCNA event. It is assumed that DCNA event is due to the gradient curvature drift of trapped non-relativistic electrons in the equatorial plane. Estimated energy of trapped electrons using azimuthal drift time for a set of ground stations within the auroral oval confirms the enhancement in electron fluxes in the same energy band as recorded by geostationary satellites GOES 13 and GOES 15. It is also noted that at Maitri, the peak to peak amplitude of these oscillation is 3-4 times larger during DCNA event 


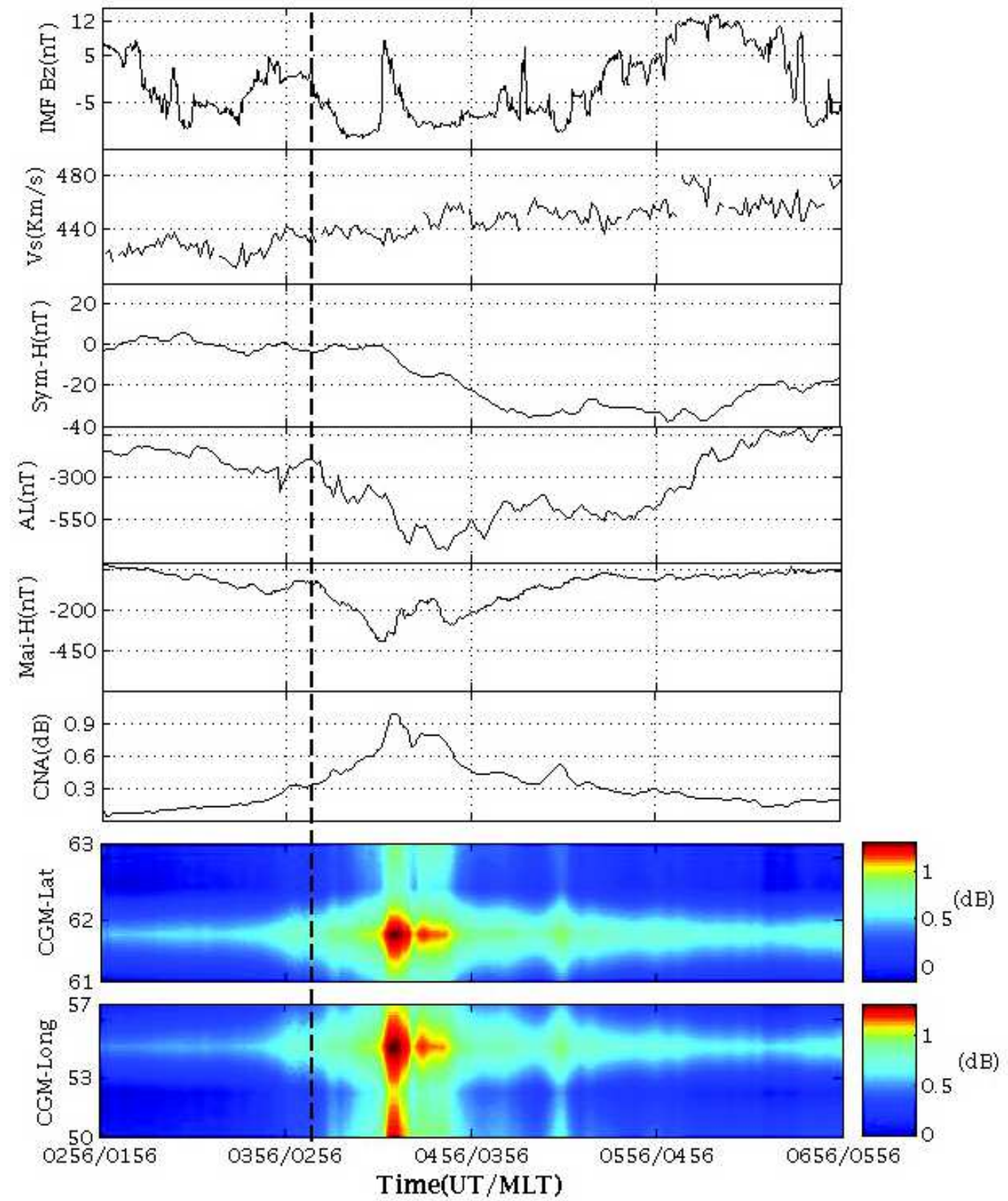

Fig. 18: CNA event at Maitri during an isolated substorm on 20 April 2011. IMF $B z$ and $V s w$ are shown in the top two panels. Next, SYM-H is shown (third panel). In response to the AL negative bay (fourth panel), westward electrojet and CNA were clearly observed (fifth and sixth panel). Last two panels show latitude and longitude extent of the absorption

(1100-1300 UT of 02 April, 2011) than those observed for non DCNA event (1000-1200 UT of 14 July, 2011) as depicted in Fig. 22. This indicates the presence of pronounced Pc5 oscillations at Maitri facilitates the growth of VLF chorus waves. Hence, the reason for precipitation of electrons is expected to be the loss cone scattering caused by wave-particle interaction triggered by ULF waves.

\section{Studies on Global Electrical Circuit (GEC) from Maitri}

Global thunderstorms in the tropical region are believed to maintain the global electric potential difference of $\sim 300 \mathrm{kV}$ between the ionosphere and the Earth's surface (Wilson, 1925). The fair weather electric field is directed from the ionosphere to the ground (Alderman and Williams, 1996). The atmospheric 

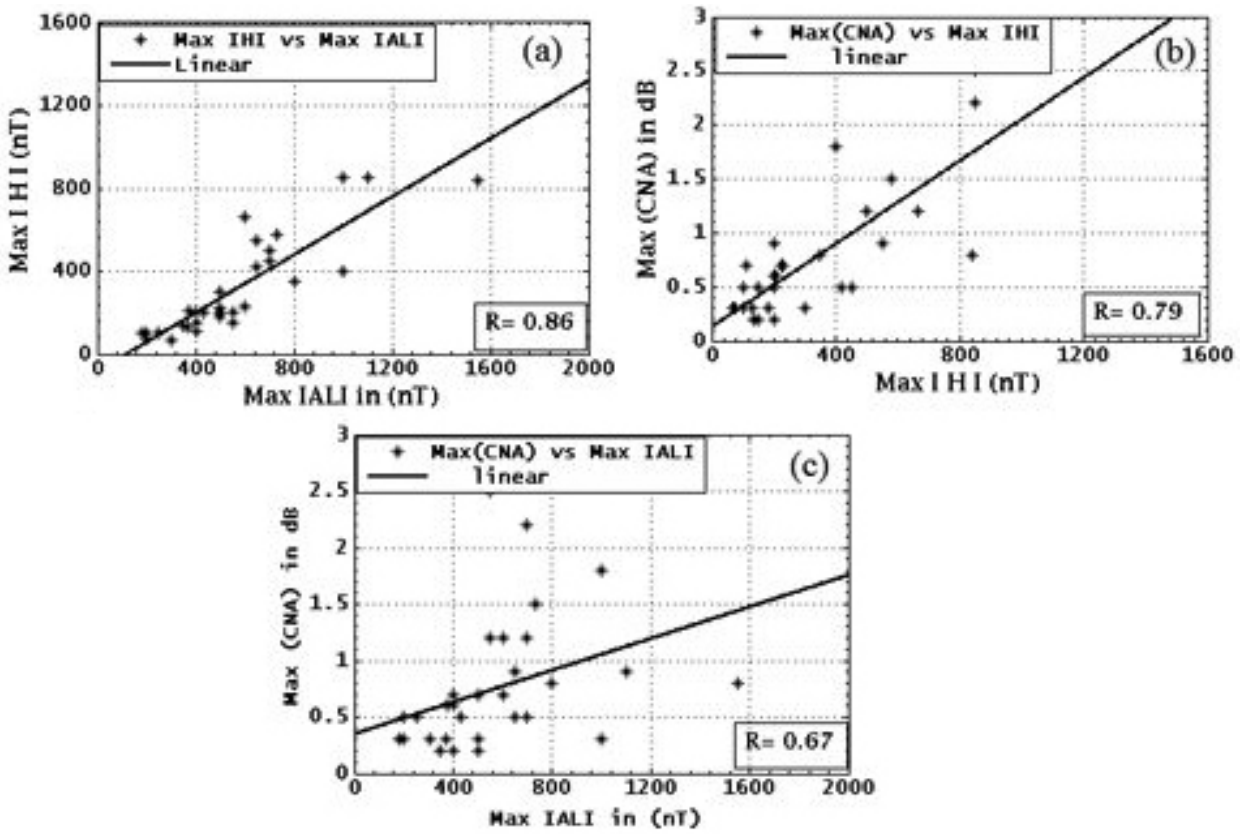

Fig. 19: Scatter plot of the maximum intensities of (a) $V s w$ vs CNA (correlation coefficient, $r=0.5$ ), (b) southward IMF Bz vs CNA $(r=0.75)$ and $(c)$ duskward IEF Ey vs CNA $(r=0.85)$ for selected events. CNA intensity at Maitri has strong dependence on IEF Ey

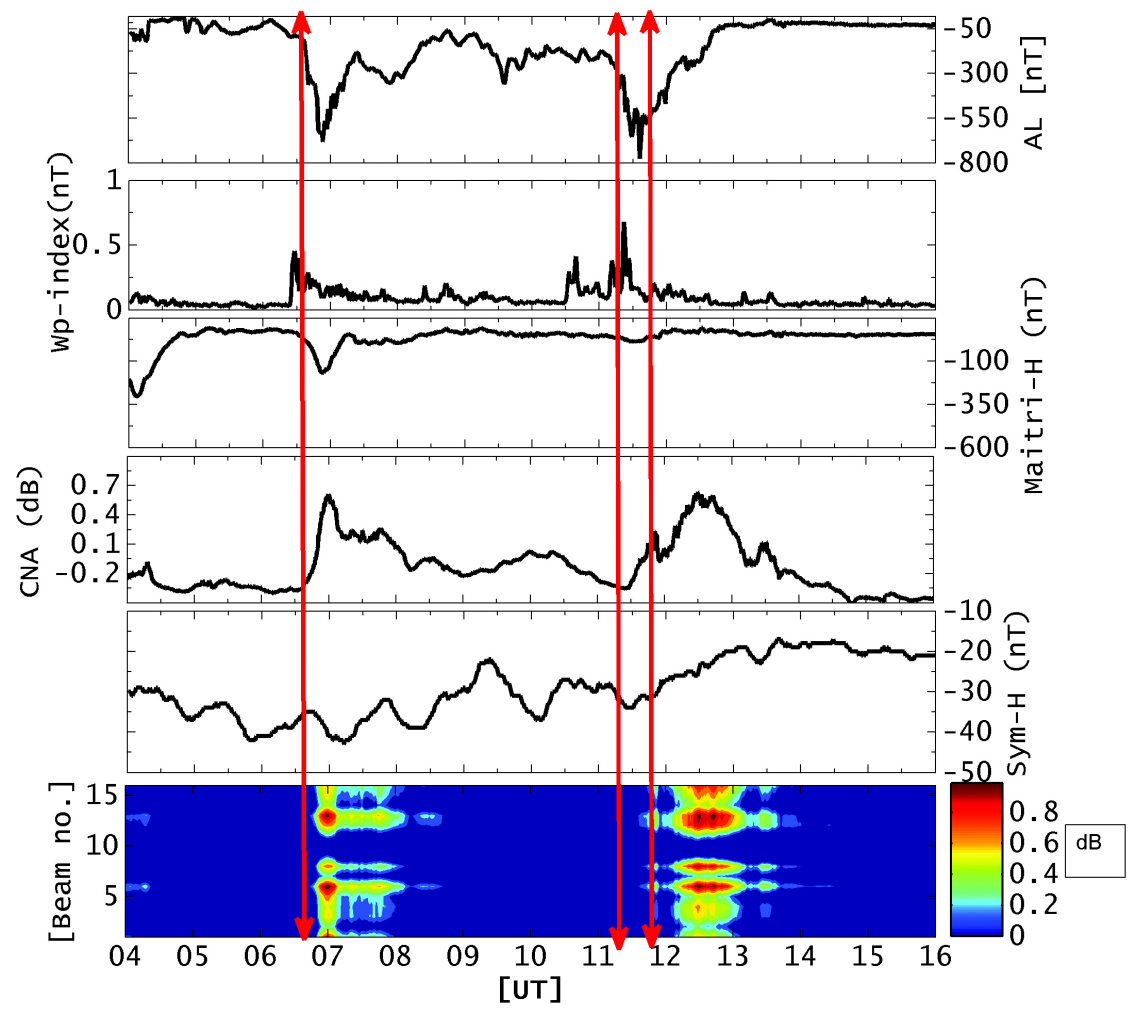

Fig. 20: Ground signatures of CNA events on 02 April 2011 at Maitri. The two upper most panels show AL-index and Wp-index, respectively. Third and fourth panels represent the variation in the horizontal component of geomagnetic field and wide beam CNA at Maitri, respectively. Sym-H has been plotted in the second bottom most panel and the last panel shows the keogram of the imaging Riometer. The extreme left solid line indicates the onset of auroral substorm absorption events where as middle solid line represent the onset of the second substorm and extreme right solid line shows the onset of CNA at Maitri. The delay between the onset of substorm and CNA onset at Maitri is a typical characteristics of DCNA 


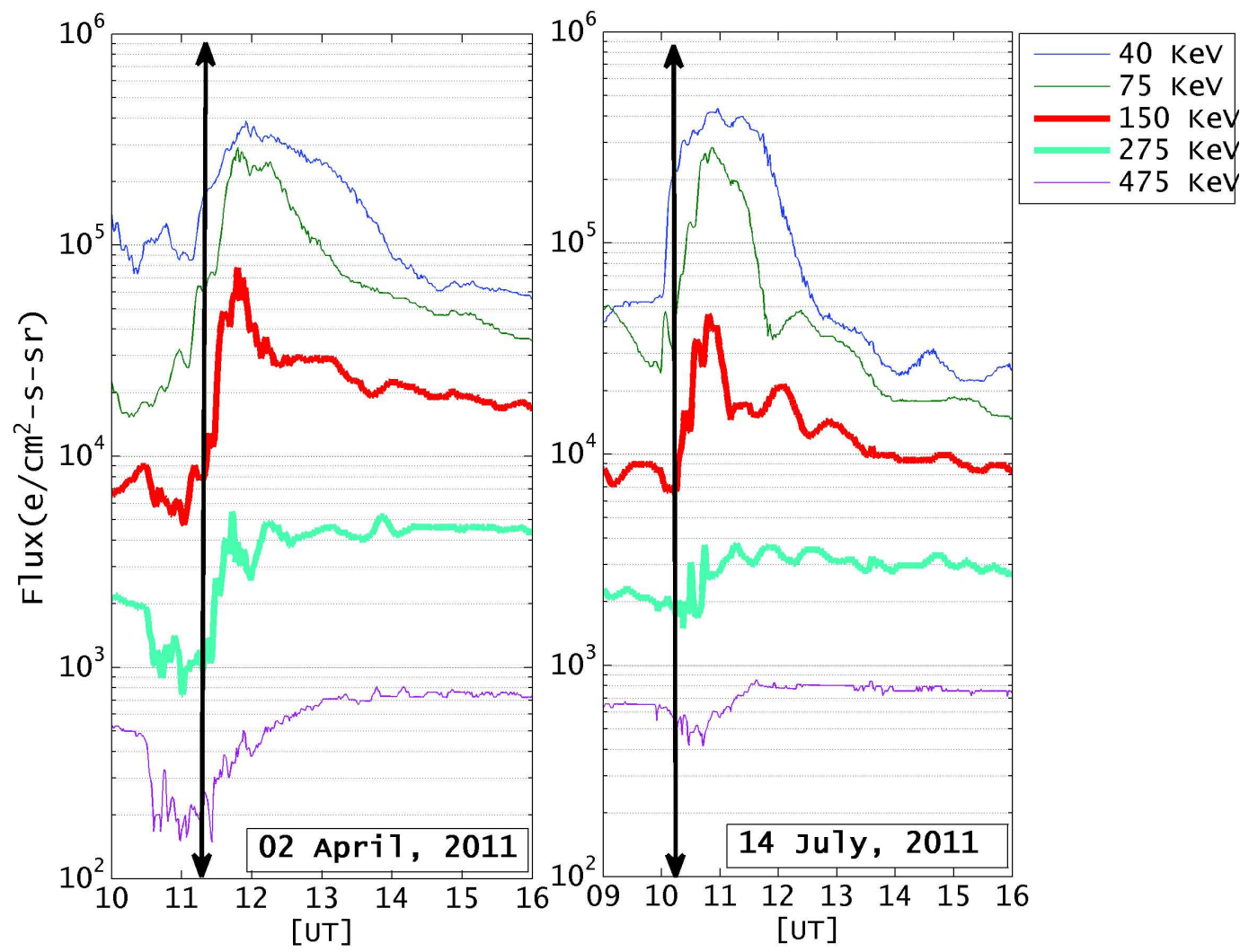

Fig. 21: 1 minutes resolution data of 40-475 KeV electron flux densities by GOES-13 for 02 April 2011 and 14 July, 2011 . Solid bars both the panels indicate the onset of substorm for these days for example 1120 UT is the onset time of susbtom on 02 April, 2011 and 1010 UT is the onset time of substorm on $14 \mathrm{July,} 2011$
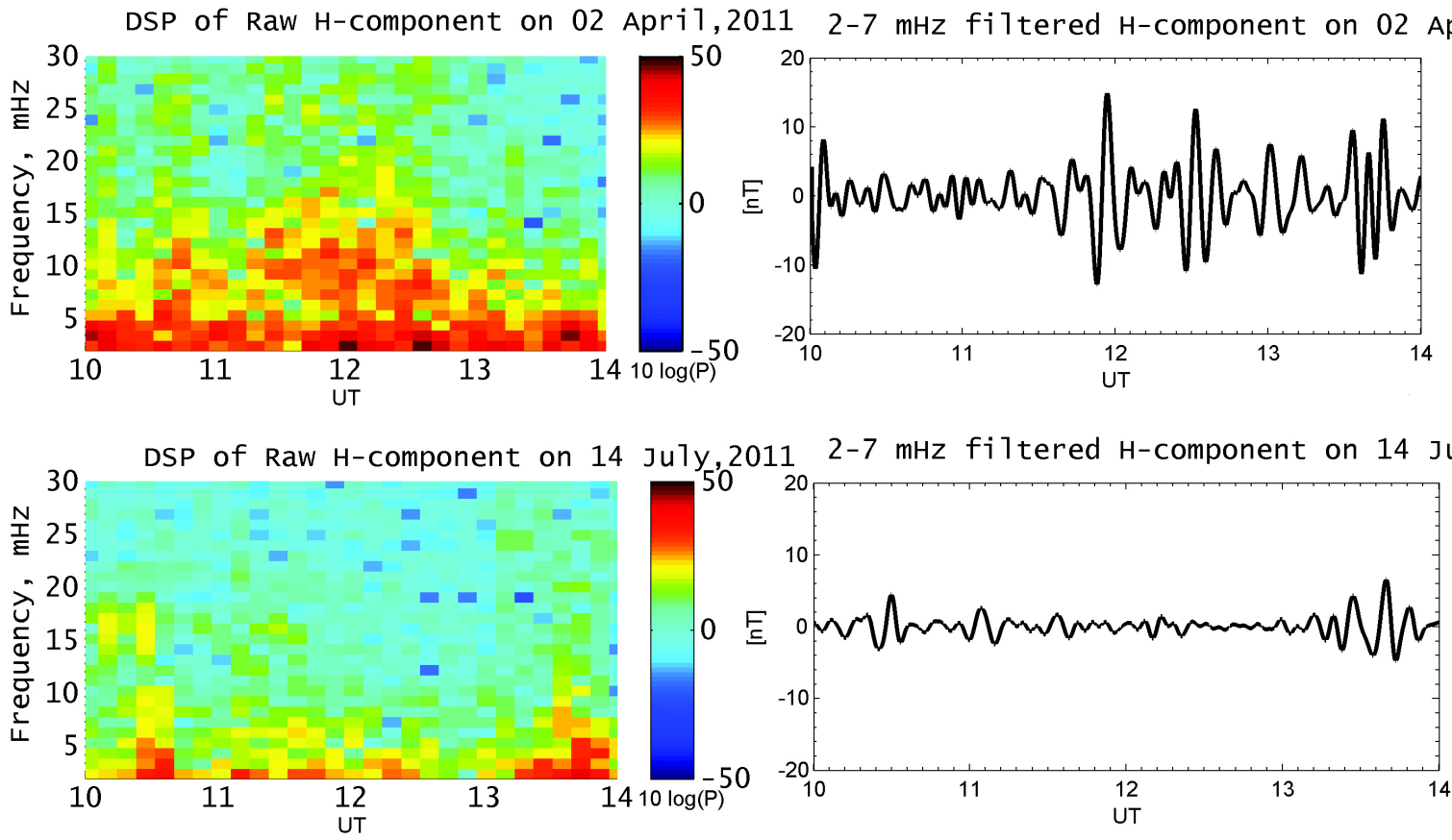

Fig. 22: (a) and (b) show the dynamics spectra of raw H-component at Maitri location on 02 April, 2011 and 14 July, 2011 respectively. (c) and (d) represent the filtered $H$ component in Pc5 pulsation range ( 1-7 mHz) on 02 April,2011 and 14 July, 2011 respectively 
electrical parameters of concern to the global electric circuit are the vertical electric field, conductivity and total current density. GEC provides an excellent platform to explore interconnections and coupling of various regions of the atmosphere. It can also provide information on the solar-terrestrial weather relationship. The GEC is also useful in exploring one of the traditional scientific problems, namely, that of associating changes in surface weather with the solar output (Herman and Goldberg, 1978). The modern view of GEC incorporates solar wind-magnetosphere dynamo and ionospheric dynamo as sources other than global thunderstorm activity. In this context, studies on GEC provide us an opportunity to address environmental changes due to space weather activity, which include geomagnetic storms, magnetospheric substorms, solar proton events, etc.

For useful measurements of GEC parameters, the observing site is required to be free of atmospheric aerosols or anthropogenic activity and should be above the atmospheric boundary layer or where convective activity is negligible. Indian sites in Antarctica meet these requirements. Further, measurements from Antarctica also allow us to investigate meteorological effects, such as blizzards, wind turbulence, snowfall and clouds, on local electrical processes and enable us to understand the electrical climate of the Antarctic plateau (Cobb 1977; Kamra et al., 2009; Minamoto and Kadokura 2011; Siingh et al., 2013).

Initial studies have shown that during magnetically quiet and moderate conditions, the variations of measured atmospheric electrical parameters tend to be similar to the behaviour expected from the Carnegie curve, which was based on several cruise measurements carried out during 1920s (Panneerselvam et al., 2007). However, during geomagnetically disturbed conditions the diurnal pattern is often found to be different from the Carnegie curve and is modified by the ionospheric/ magnetospheric contributions. This study was carried out with the help of surface measurements of the atmospheric electrical parameters like Maxwell current, electric field and conductivity obtained from Maitri (117m MSL) during the austral summer from 2001 to 2004. Using long-term data sets, Jeeva et al. (2016) reported anomalous diurnal pattern of the atmospheric electric potential gradient and air-Earth current density on several days. This behaviour was ascribed to regional phenomena like katabatic winds bringing in space charge from the polar plateau.

Victor et al. (2015) discussed the variations of the atmospheric vertical electric field measured at Maitri and the polar station, Vostok $\left(78.5^{\circ} \mathrm{S}, 107^{\circ} \mathrm{E}\right)$, during the geomagnetic disturbances on 25-26 January 2006. The departure of the field at Maitri, as observed in Fig. 23, during disturbed periods has been attributed to the magnetosphere-ionosphere coupled voltage generator. Digital Fluxgate Magnetometer data at Maitri were used to identify the presence of auroral electrojet (Fig. 24). Adopting the solar windmagnetosphere coupling function $(\varepsilon)$ as a measure for the energy and momentum transfer from the solar wind, Kumar et al. (2009) showed that the atmospheric electrical parameters are well correlated to the coupling function during geomagnetic disturbances (Fig 25). However, the correlation breaks down during minor storms and sub-storm events.

For the first time, studies have been carried out on the influence of a major geo-effective storm (Kp $=8$ ) on 5 April 2010 on the atmospheric electrical parameters measured at three high-latitude stations in the Antarctic plateau (Victor et al., 2016). The objective was to identify the nature of the dawn-todusk convection cell and its impact on the electrical parameters monitored on the ground. Three consecutive substorms were identified from the

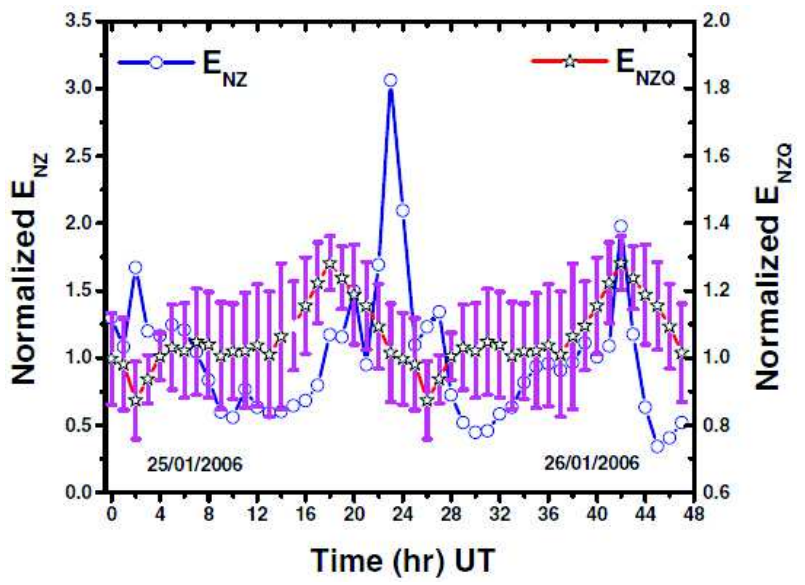

Fig. 23: Comparison of observed atmospheric electric filed (ENZ) on 25-26 January 2006 and $E_{N Z Q}$ at Maitri, Antarctica. Right side axis represents the normalized value for reference curve. Left side axis represents the normalized value of electric field at Maitri 

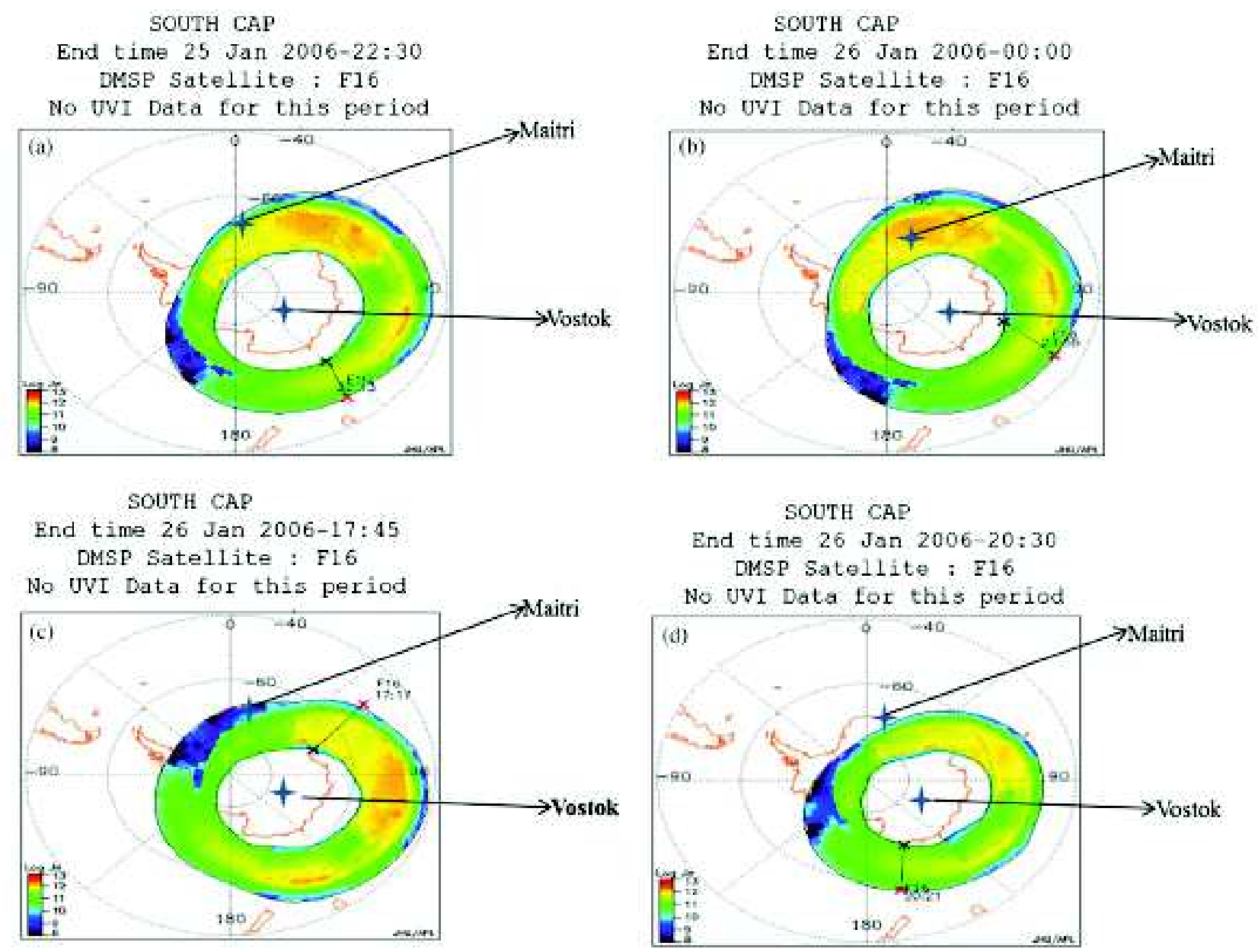

Fig. 24: The relative position of Maitri and Vostok compared to the auroral oval on 25-26 January 2006. (a) Auroral oval position over south polar cap at 22:30 UT on 25 January 2006; (b) at 00:00 UT on 26 January 2006; (c) at 17:45 UT on 26 January 2006; and (d) auroral oval position over south polar cap at 20:30 UT on 26 January 2006

magnetic records at Maitri. It was inferred that the variation in the amplitude of the potential gradient (PG) depends on the magnetic latitude during the substorm onset. During the substorm expansion phase, when the convection cell is overhead, PG is significantly enhanced due to the downward mapping of the ionospheric horizontal electric field. The deviation of PG with respect to the typical diurnal reference curves clearly indicates that the spatio-temporal variations of the ionospheric convective electric field significantly alter the atmospheric electric field measured over the three high latitude stations as shown in Fig. 26.

Schumann resonances (SRs) are the AC components of GEC and are excited by the lightning activity within the Earth-ionosphere waveguide. The study reveals a strong UT variation of amplitude in seasonal as well as yearly timescales. The diurnal trend in the amplitude is retained irrespective of seasons, whereas significant differences are noticed in the frequency behavior between the summer and winter seasons, especially in the EW component. The observed diurnal variation is explained in terms of the dominant thunderstorm activity centered over the three convectively active regions; Asia/Maritime Continent (Indonesia), South America and Africa. The diurnal variation in frequency depends not only on the location of the thunderstorm region with respect to the observer, but also on the ionospheric day/night conditions and the Earth-ionosphere cavity thickness (Manu et al. 2015). 

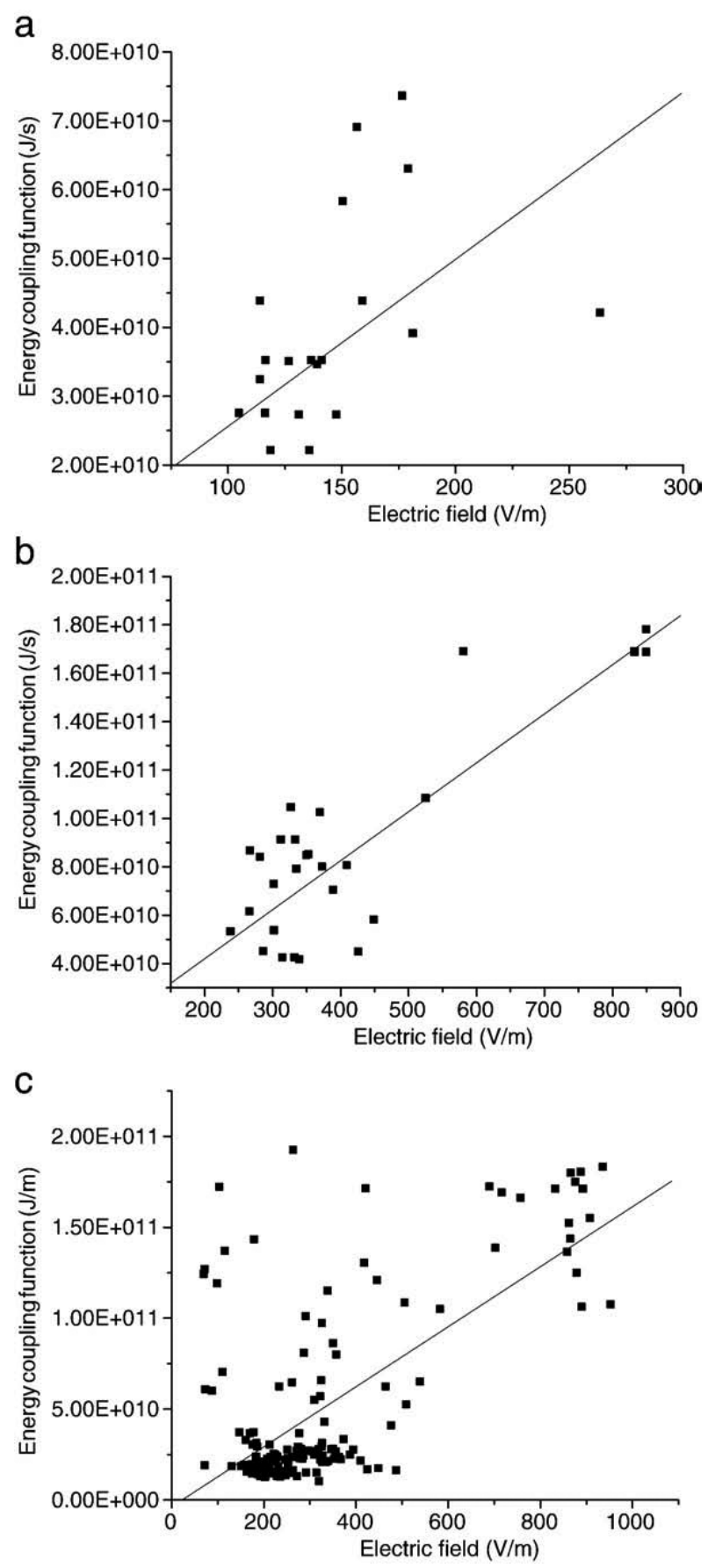

Fig. 25: (a, b, c) Electric field plotted against energy coupling function for magnetically disturbed days

GPS Measurements for Crustal Deformation, Mass Balance and Ice Dynamics of Nivlisen Ice Shelf and Tropospheric Studies

The satellite based navigation and surveying technique Global Positioning System (GPS) is a widely used tool to acquire measurements for Earth sciences as well as Atmospheric sciences. As a consequence of

earthquake and plate tectonics, this space geodetic technique has a major impact on the study of problems of regional and local tectonics by making accurate measurements of the positions of point marks attached to earth. The aim of these types of observations is to determine the changes in the position of points on Earth's surface, determining the strain accumulation in the region, caused by seismic activities in the Earth's crust. Since the Antarctic Plate consists of divergent plate boundaries, broken by numerous large structures and Ice mass, this precise geodetic measurement can shed light on the deformation occurring in Antarctica.

GPS provides an opportunity to investigate many important dynamic processes in the troposphere. The tropospheric error is the effect of the neutral atmosphere on GPS signals. This error contains a dry and wet component. Assuming that the Earth's atmosphere is in hydrostatic equilibrium, the dry component only depends on the atmospheric pressure at the surface. For geodetics, the tropospheric effect is a disturbance that has to be removed from the measurements. But for meteorologists, this effect is an interesting signal that can give relevant information concerning the small-scale and short-term variations in the water vapor content (Braun et al., 2001).

Global positioning system (GPS) campaigns were conducted during two austral summer seasons to obtain insight into the velocity and strain-rate

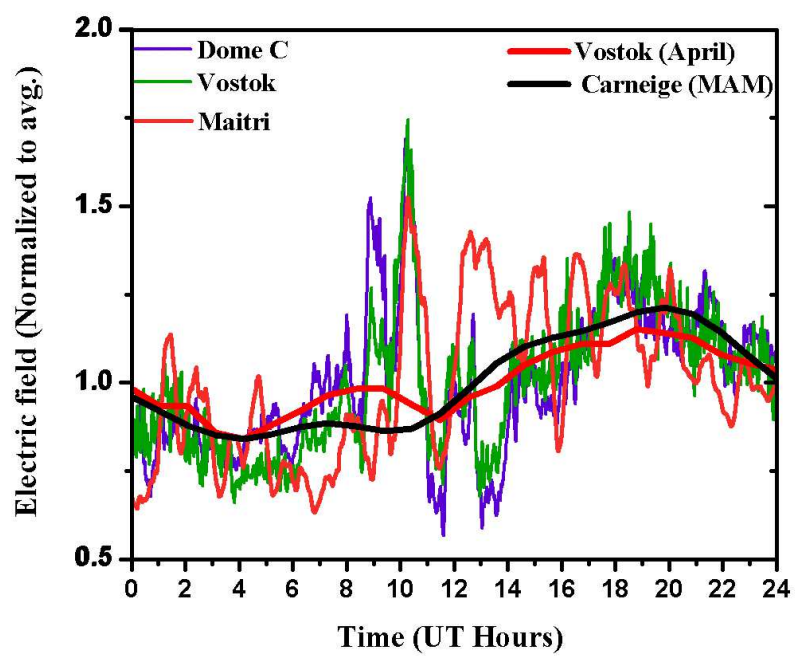

Fig. 26: Diurnal variation of normalized potential gradient for three highlatitude stations on 5 April 2010, intervals II and III are shaded. Averaged atmospheric electric field variation on April at Vostok and MAM period from Carnegie observation over plotted 
distribution on Schirmacher Glacier, central Dronning Maud Land, East Antarctica (Fig. 27). GPS data collected at 21 sites was analyzed to estimate the site coordinates, baselines and velocities. The short term precession of the base station, MAIT, was estimated from the daily coordinates repeatability solutions. All GPS points on the glacier were constrained with respect to MAIT and nearby International GPS Service stations. Horizontal velocities of the glacier sites were estimated to lie between $1.89 \pm 0.01 \mathrm{ma}^{-1}$ and $10.88 \pm 0.01 \mathrm{ma}^{-1}$ to the north-northeast, with an average velocity of $6.21 \pm 0.01 \mathrm{ma}^{-1}$. The principal strain rates provide a quantitative measurement of extension rates, which range from $(0.04 \pm 0.02) \times 10^{-}$ ${ }^{3}$ to $(0.96 \pm 0.16) \times 10^{-3} \mathrm{a}^{-1}$. The velocity and strain rate distributions across the GPS network in Schirmacher Glacier were spatially correlated with topography, subsurface undulations, fracture zones/ crevasses and the partial blockage of the flow by nunataks and the Schirmacher Oasis (Sunil et al., 2007).

Mass Balance and Ice Dynamics of Nivlisen ice Shelf in Antarctica: GPS were operated at equally distributed four sites over Nivlisen ice shelf. GPS data was collected and supplemented by GPR measurements (from other sources/institutes). The data was used to study the ice thickness distribution, velocity and mass balance of the ice shelf.

Using Global Positioning System (GPS) receiver, 19 days of continuous GPS data were collected from January 23 to February 10, during austral summer of 2005, in the frontal zone of Nivlisen Ice Shelf (NIS) of central Dronning Maud Land (cDML), East Antarctica. GPS data were analyzed to estimate the diurnal and semi-diurnal variations (Fig. 28). We

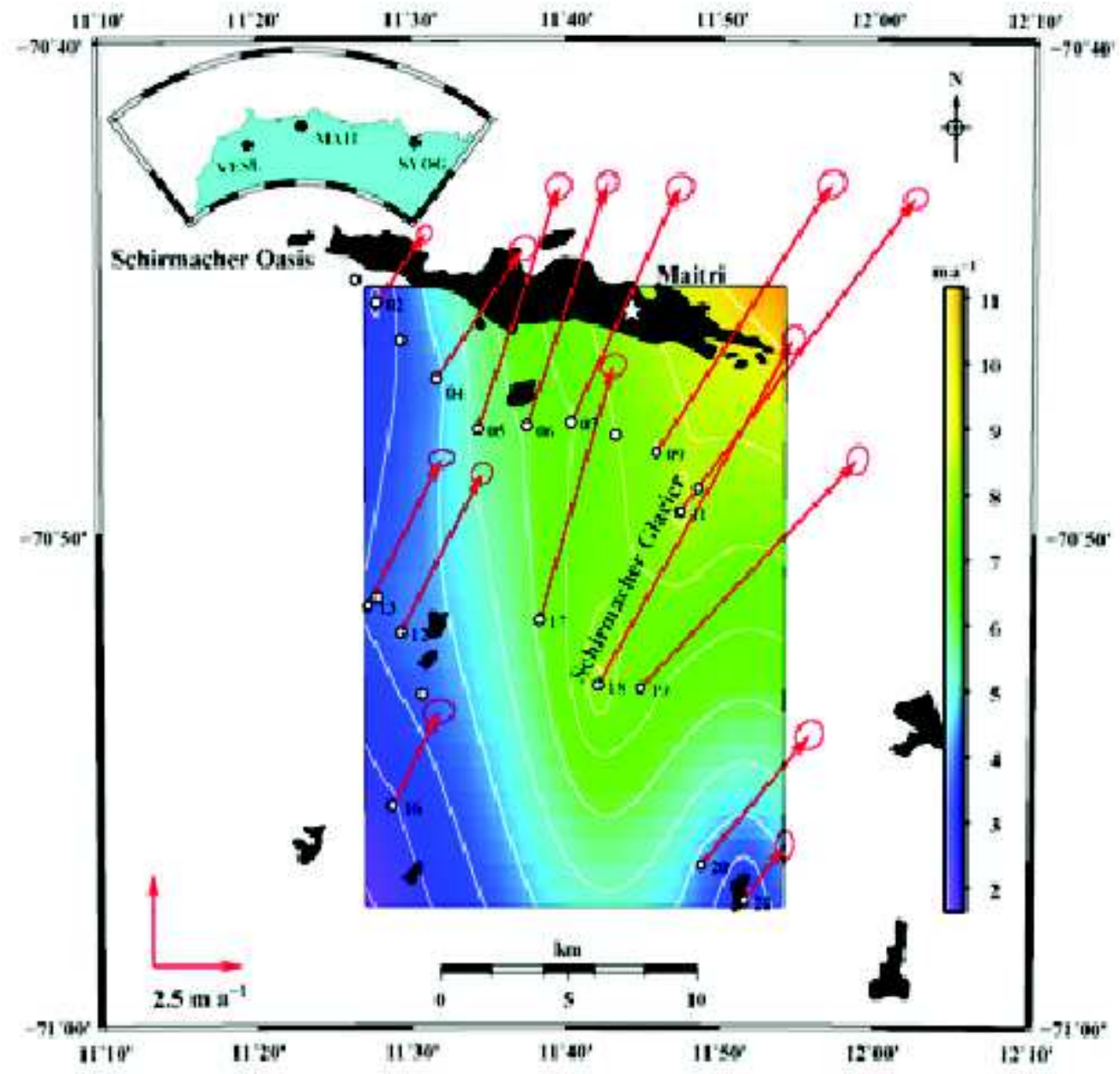

Fig. 27: Horizontal velocity vectors (with 95\% confidence ellipses) for the GPS network on Schirmacher Glacier, superimposed on a shaded relief velocity-distribution map with $1 \mathrm{~m}$ contour interval obtained from the GPS velocity field 


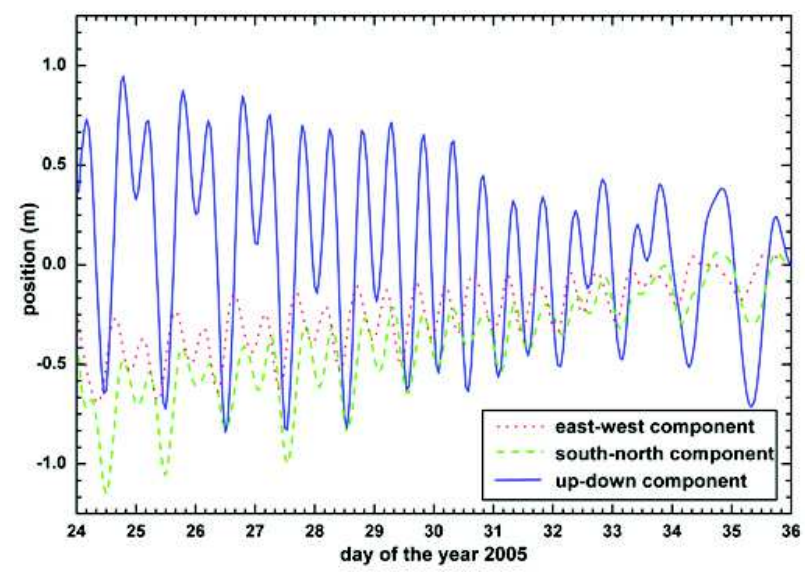

Fig. 28: Low-pass filtered position time co-ordinates of NIS GPS site at NIS

constrained the GPS sites at NIS with the base station MAITRI at Schirmacher Oasis and nearby International GNSS Service (IGS) stations. It is found that, the ice shelf motion in both horizontal and vertical were caused by the combination of ocean tidal effect, wind stress and ocean currents. The estimated horizontal velocity at NIS GPS site was $0.72 \mathrm{~m} /$ day towards north-northeast with an azimuth of $20.27^{\circ}$. Major constituents of the oceanic tide have been delineated from the hourly time series data by FFT analysis. The amplitudes of the diurnal and semidiurnal estimated were $\sim 1.25 \mathrm{~m}$ and $0.5 \mathrm{~m}$, respectively. The results indicate not only the expected vertical tidal displacement but also a significant variation in the horizontal velocity of NIS. A phase shift with maximum forward velocity occurred about 3-4 hours after the maximum tidal height, suggests the additional role of ocean currents as one of the driving forces for the ice shelf movement. Further, this type of precise observations of diurnal and semidiurnal tidal constituents can be assimilated in the models (Sunil et al., 2008).

\section{Magnetic Anomaly Map of Bharati Promontory}

A magnetic survey of Bharati promontory was carried out to compile a magnetic anomaly map of the area (Reddy and Dhar, 2007). It is observed that the high magnetic field anomaly regions are concentrated over some pockets which are located on high ridges. The causative source of the anomaly seems to be at very shallow depth as horizontal gradient of about 1000nT per $50 \mathrm{~m}$ were observed at some locations. The most likely candidate for the magnetic anomaly can be the magnetite bearing gneisses/amphibolitic gneisses which are present as NE-SW trending bands in the region. There are evidences of oxidation of iron rich material as seen in the form of limonitic surface exposures.

\section{Environmental Magnetism}

The Antarctic climatic and environmental variability can be studied by harnessing mineral magnetic techniques. Environmental magnetic measurements provide a means to accurately assess environmental variability at millennial to decadal timescales and to trace out the provenance (sediment source linkage) of the sediments deposited within and around the Antarctic region. The distribution of sediments within and around Antarctica is controlled by a tectonically active regime. This region has a prevalence of icebergs, glacial outwash and redistribution of bottom currents, transport and vertical rain-wash of biogenic and eolian material. Magnetic properties provide the potential for reconstructing ice sheet fluctuations both at millennial ( short) and orbital ( long) timescales (Loulergue et al., 2008).

Mineral magnetic study was carried out on sediment cores collected from two East Antarctica lakes such as Priyadarsini Lake (L49) and Schirmacher Oasis Lake (L6). Continuous, highresolution measurements of rock magnetic parameters were measured at IIG Environmental Magnetism Laboratory to characterize the magnetic mineralogy and grain size, which are used to reconstruct depositional paleoenvironments and paleoclimate in the region. The magnetic analysis provided the means in terms of environmental magnetic techniques for core-correlation between Antarctica lake sites. Magnetic susceptibility and remnant magnetization measurements were done by using MFK1-FA Kappabridge and JR6 Spinner Magnetometer respectively. Frequency dependent susceptibility showed the presence of superparamagnetic (SP) grains in both the cores pointing at periods of lower glacial activity. Magneto mineralogical S-Ratio values showed the presence of Hematite in the upper part and Magnetite in the lower part of the cores. The influx of these magnetic minerals to the lakes is largely attributed to change in source of sedimentation derived from local glacial activities in and around these lake environments as well as sources remote from Antarctica continent. This environmental magnetic 
study has therefore proved to be potential for development of high resolution magnetic proxy data to reconstruct palaeoclimate changes during the past 20,000 years, beginning from Last Glacial Maximum from the least studied area like Antarctica (Ruddiman et al., 1976; Pant et al., 2005).

\section{Conclusion}

Indian Institute of Geomagnetism (IIG) is continuously contributing to polar research in India right from the launching of India's first scientific expedition to Antarctica. The role of IIG in the research of geomagnetic and allied field at Antarctica is significant. Contributions of field staff to be noted such as training, initiative, commissioning of several experiments and in data acquisition. The major findings such as rapid decline of total Magnetic field as observed at and near Maitri, SQ variations with season along with the experiments such as triangulation magnetometer study, conjugate geomagnetic observations etc., are significant. Researchers of IIG have significantly contributed to the substorm research with the help of magnetic data from Indian Antarctic stations viz. Maitri and Bharati. Dynamics of susbtorms as observed from Maitri and Bharati, morphological study of auroral electojet and study of susbtorms which lie poleward of the standard auroral oval are some of the important contributions to substorm research. The particle precipitation dynamics during geomagnetic activities resulting in auroral activity, can affect the HF communication and result in cosmic noise absorption to a greater extent. Data obtained from highly sophisticated Imaging Riometer operating in tandem with magnetometer along with supporting satellite data can throw light on the mechanism of wave-particle interaction responsible for particle acceleration and precipitation in the inner magnetosphere. The study of Global Electric Circuit (GEC) has been significantly strengthening our understanding of near Earth electrical environment at Antarctica and has been helpful in establishing a link between the surface electrical environment and space weather events. Furthermore, long data sets of AC part of the GEC obtained from inductioncoil magnetomaters operating at both the Antarctic stations can provide an estimate of global temperature and hence will be helpful in global climate study. Global Positioing System (GPS) is used as geodetic technique which has a major impact on the study of problems of regional and local tectonics by making accurate measurements

Global positioning system (GPS) campaigns conducted to obtain insight into the velocity and strainrate distribution on Schirmacher Glacier, central Dronning Maud Land, East Antarctica from 21 sites indicated the horizontal velocities of the glacier sites to lie between $1.89 \pm 0.01 \mathrm{ma}^{-1}$ and $10.88 \pm 0.01 \mathrm{ma}^{-1}$ to the north-northeast, with an average velocity of $6.21 \pm 0.01 \mathrm{ma}^{-1}$. The principal strain rates provide a quantitative measurement of extension rates, which range from $(0.04 \pm 0.02) \times 10^{-3}$ to $(0.96 \pm 0.16) \times 10^{-3} \mathrm{a}^{-}$ 1 . Such studies have been conducted for the first time in this region.

The GPS data collected from the frontal zone of Nivlisen Ice Shelf (NIS) of central Dronning Maud Land (cDML), East Antarctica to estimate the diurnal and semi-diurnal variations revealed that the ice shelf motion in both horizontal and vertical were caused by the combination of ocean tidal effects, wind stress and ocean currents. The results suggest the additional role of ocean currents as one of the driving forces for the ice shelf movement. Further, this type of precise observations of diurnal and semi-diurnal tidal constituents can be assimilated in the future models.

Mineral magnetic studies carried out on sediment cores collected from two East Antarctica lakes such as Priyadarsini Lake (L49) and Schirmacher Oasis Lake (L6) provided the means in terms of environmental magnetic techniques for corecorrelation. The study has therefore proved to be potential for development of high resolution magnetic proxy data to reconstruct palaeoclimate changes during the past 20,000 years, beginning from Last Glacial Maximum from the least studied area like Antarctica. This part of studies are in pipeline and will be undertaken in near future.

\section{Acknowledgments}

The authors are grateful to Indian Institute of Geomagnetism for encouragement and support to Antarctic Geomagnetism project. The hard work and efforts of all the scientists from IIG, who have participated in Indian Antarctic Expeditions, collected good quality geomagnetic data on a regular basis and contributed to these studies and their contributions are gratefully acknowledged. We are grateful to 
ESSO-NCAOR for arranging annual Antarctic expeditions and providing full logistic support to enable participating scientific organizations to carry out scientific studies.

\section{References}

Adlerman E J and Williams E R (1996) Seasonal variation of the global electrical circuit Journal of Geophysical Research: Atmospheres 101 29679-29688

Arun T, Patil A G, Dhar A and Rajaram G (2000) Rapid decrease in total magnetic field intensity at Indian Antarctic station Maitri in J Indian Geophys Union 4 119-128

Banola S, Dhar A and Rajaram G (1997) Movement of Indian Antarctic station Maitri into Auroral Oval during Geomagnetic activity Technical Report of Thirteenth Indian Expedition to Antarctica, Technical Publication No. 11, Dept. of Ocean Development, New Delhi, pp. 91-105

Behera J K, Sinha A K, Singh A K, Geeta Vichare, Dhar A, Labde $S$ and Jeeva K (2015) Substorm related CNA near equatorward boundary of the auroral oval in relation to interplanetary conditions in Adv Space Res 56 28-37, DOI: 10.1016/j.asr.2015.03.036

Behera, J K, Sinha A K, Vichare G, Kozyreva O, Rawat R and Dhar A (2016) Dayside cosmic noise absorption at the equatorward boundary of auroral oval as observed from Maitri, Antarctica $\left(\mathrm{L}=5\right.$; CGM $\left.62.45^{\circ} \mathrm{S}, 55.45^{\circ} \mathrm{E}\right), J$ Geophys Res Space Physics 121 3198-3211 doi: 10.1002/ 2016JA022418

Behera, K Jayanta, Sinha A K, Singh A K, Rawat R, Vichare G, Dhar A, Pathan B M, Nair K U, Selvaraj C and Elango P (2014) First results from imaging riometer installed at Indian Antarctic station Maitri J Earth Syst Sci 123 593-602

Bormann P, Schafer U, Kopsch C and Wagner S (1995) Geophysical investigations, In: The Schirmacher Oasis, Queen Maud land, East Antarctica and its surroundings, Gautha P. Bormann and D. Fritzsche (eds), Germany, Justus Perthes, $38-57$

Braun J, Rocken C and Ware R (2001) Validation of line-of-sight water vapor measurements with GPS Radio Science $\mathbf{3 6}$ 459-472

Browne S, Hargreaves J K and Honary B (1995) An imaging riometer for ionospheric studies Electronics \& communication engineering journal 7(5) 209-217

Cobb W E (1977) Electrical Process in Atmospheres (eds) Dolezalek H and Reiter R (Darmstadt: Steinkopff) 161167

Codrescu M, Fuller-Rowell T, Roble R and Evans D (1997) Medium energy particle precipitation influences on the mesosphere and lower thermosphere in J Geophys Res 102 977-19,987

Codrescu M V, Fuller-Rowell T J, Roble R G and Evans D S (1997) Medium energy particle precipitation influences on the mesosphere and lower thermosphere $J$ Geophys Res 102 977-19987

Davis T and M Sugiura (1996) Auroral electrojet activity index $\mathrm{AE}$ and its universal time variations in J Geophys Res $\mathbf{7 1}$ 785-801

Detrick D L and Rosenburg T J (1990) A Phased-Array Radio wave Imager for Studies of Cosmic Noise Absorption Radio Sci 25 325-338

Dhar A, Kalra R, Jeeva K, Unnikrishnan K, Daga D M and Rajaram G (1993) Changes in position and intensity of auroral electrojet inferred from conjugate area studies Presented at INDO-RUSSIAN Symposium on 'Nature and Variations of the Geomagnetic Field' held at New Delhi

Dhar A, Patil A, Sankaran S and Rajaram G (1999) Three-station Magnetometer experiment at Antarctica during Jan-1996 to determine the velocity of disturbed-Time overhead Auroral current system (In Scientific Report of Fifteenth Indian Expedition to Antarctica, Technical Publication No. 13, Dept. of Ocean Development, New Delhi, pp. 1-20)

Frank-Kamentsky A and Troshichev O (2011) A relationship between the auroral absorption and the magnetic activity in the polar cap Journal of Atmospheric and SolarTerrestrial Physics 77 40-45

Glatzmaier G A and Roberts P H (1995) A three-dimensional self-consistent computer simulation of a geomagnetic field reversal Nature 377 203-209

Gubbins D (1988) Thermal core mantle interactions and time averaged paleomagnetic field Journal of Geophysical Research: Solid Earth 93 (1988) 3413-3420

Hargreaves J K (1969) Auroral Absorption of HF Radio Waves in the Ionosphere: (1969) A Review of Results from the First Decade of Riometry Proceedings of the IEEE 57 1348-1373

Herman J R and Goldberg R A (1978) Initiation of non-tropical thunderstorms by solar activity Journal of Atmospheric and Terrestrial Physics 40 121-134

Jeeva K, Gurubaran S, Williams E R, Kamra A K, Sinha A K, Guha A and Dhar A Anomalous diurnal variation of atmospheric potential gradient and air Earth current density observed at Maitri, Antarctica Journal of Geophysical Research: Atmospheres 121 593-12, 611, doi: 10.1002/ 2016JD025043

Kalra R, Dhar A, Unnikrishnan K, Jeeva K, Daga D M and Rajaram G (1995) Changes in Auroral Electrojet currents 
Inferred from Geomagnetic Field variations at Maitri and Northern Conjugate stations Scientific \& Technical Report of Eleventh Indian Expedition to Antarctica, Technical Publication 9 Dept of Ocean Development, New Delhi, pp. $87-101$

Kalra R, Hanchinal A N, Sridharan M and Rajaram G (1998) Three station Fluxgate Magnetometer experiment to determine auroral current velocities over Indian Antarctic stations. Scientific Report of Fourteenth Indian Expedition to Antarctica, Technical Publication 12 Dept. of Ocean Development, New Delhi, pp. 47-55

Kamide Y and Rostoker G (2004) What is the physical meaning of AE index? EOS Trans AGU 85 188-192

Kamide Y and Akasofu S-I (1983) Notes on the auroral electrojet indices in Rev Geophys 21 1647-1656

Kamide Y and Kokubun S (1996) Two component auroral electrojet: Importance for substorm studies Journal of Geophysical Research: Space Physics 101 13027-13046

Kamra A K, Siingh D and Pant V (2009) Scavenging of atmospheric ions and aerosols by drifting snow in Antarctica Atmospheric Research $91215-218$

Kavanagh A J, Honary F, McCrea I W, Donovan E, Woodfield E E, Manninen J and Anderson P C (2002) Substorm related changes in precipitation in the dayside auroral zone - a multi instrument case study Ann Geophys 20 1321-1334

Kellerman A C and Makarevich R A (2011) The response of auroral absorption to substorm onset: Superposed epoch and propagation analyses Journal of Geophysical Research: Space Physics 116

Kirkwood S, Osepian A, Belova E, Urban J, Pérot K and Sinha K (2015) Ionization and NO production in the polar mesosphere during high-speed solar wind streams: model validation and comparison with $\mathrm{NO}$ enhancements observed by Odin-SMR. In Annales Geophysicae (Vol. 33, No. 5, pp. 561-572)

Kumar CA, Panneerselvam C, Nair K U, Jeyakumar H J, Selvaraj C, Gurubaran S and Venugopal C (2009) Apposite of atmospheric electric parameters with the energy coupling function (å) during geomagnetic storms at high latitude Atmospheric Research 91 201-205

Little C G and Leinbach H (1959) The riometer-a device for the continuous measurement of ionospheric absorption Proceedings of the IRE 47 315-320

Loulergue L, Schilt A, Spahni R, Masson-Delmotte V, Blunier T, Lemieux B and Chappellaz J (2008) Orbital and millennialscale features of atmospheric $\mathrm{CH} 4$ over the past 800,000 years Nature 453 383-386
Manu S, Rawat R, Sinha A K, Gurubaran S and Jeeva K (2015) Schumann resonances observed at Maitri, Antarctica: diurnal variation and its interpretation in terms of global thunderstorm activity Current Science 109784

McPherron R L, Russell C T, Kivelson M G and Coleman P (1973) Substorms in space: the correlation between ground and satellite observations of the magnetic field in Radio Sci 8 1059-1076

Minamoto Y and Kadokura A(2011) Extracting fair-weather data from atmospheric electric-field observations at Syowa Station, Antarctica Polar Science 5 313-318

Murphy K R, Mann I R, Rae I J, Walsh A P and Frey H U (2014) Inner magnetospheric onset preceding reconnection and tail dynamics during substorms: Can substorms initiate in two different regions? Journal of Geophysical Research: Space Physics 119 9684-9701

Newell P T and Gjerloev J W (2011) Evaluation of SuperMAG auroral electrojet indices as indicators of substorms and auroral power J Geophys Res 116 A12211 doi:10.1029/ 2011JA016779

Newell P T, Sotirelis T and Wing S (2010) Seasonal variations in diffuse, monoenergetic, and broadband aurora in J Geophys Res 115 A03216, http://dx.doi.org/10.1029/2009JA014805

Newell P T and Meng C (1992) Mapping the day side ionosphere to the magnetosphere according to particle precipitation technique Geophysical Research Letters 19 Doi: 10.1029/ 92GL00404

Panneerselvam C, Kumar C PA, Dhar A, Nair K U, Selvaraj C, Gurubaran S and Pathan B M (2010) Instrumentation for the surface measurements of atmospheric electrical parameters at Maitri, Antarctica: First results Earth, Planets and Space 62 545-549

Panneerselvam C, Selvaraj C, Jeeva K, Nair K U, Anilkumar C P and Gurubaran S (2007) Fairweather atmospheric electricity at Antarctica during local summer as observed from Indian station, Maitri Journal of Earth System Science 116 179-186

Pant R K, Basavaiah N, Juyal N, Saini N K, Yadava M G, Appel E and Singhvi A K (2005) A 20 ka climate record from Central Himalayan loess deposits Journal of Quaternary Science 20 485-492

Papitashvili V O, Clauer C R, Christiansen F, Kamide Y, Petrov V G, Rasmussen O, Watermann J F (2002) Near-conjugate magnetic substorms at very high latitudes observed by Greenland and Antarctic ground magnetometers and Ørsted satellite. In: R M Winglee (Ed.) Proceedings of International Conference on Substorm-6 110-114 
Pathan B M, Dhar A, Asinker R L, Selvamurugan R and Hanchinal A N (2009) Declining magnetic field at Maitri, Antarctica in Indian J Geosci 63 187-194

Rajaram G, Dhar A and Kumar A (2001) Response of Geomagnetic variations and $30 \mathrm{MHz}$ Riometer absorption, at Indian Antarctic Station Maitri, to conditions of "Zero" and "High" solar wind Adv Space Res 28 1661-1667

Rajaram G, Arun T and Dhar A (2002) Diagnostics of Magnetosphere-Ionosphere coupling over Indian Antarctic Station Maitri, from Fluxgate Magnetometer and Riometer observations during the optical Auroral event of 4-5 March 1999 Advances in Space Research 30 2195-2201

Rajaram G, Arun T, Dhar A and Patil A G (2002) Rapid decline in total magnetic field $\mathrm{F}$ at Antarctic Stations - its relationship to core - mantle features Antarctic Science 14 61-68

Rangarajan G K and Dhar A (1988) A comparative study of Quiet day Variation of the Geomagnetic field at Dakshin Gangotri (India) and Novolazarevskaya (USSR) in Antarctica (1988) Scientific Report on Fifth Indian Expedition to Antarctica DOD publication No. 5, pp. 353-361

Reddy C D and Dhar A (2008) Magnetic anomaly map for Bharati promontory, Larsemann Hills, East Antarctica Current Science 9425 March 2008

Rodger C J, Kavanagh A J, Clilverd M A and Marple S R (2013) Comparison between poes energetic electron precipitation observations and riometer absorptions Implications for determining true precipitation fluxes Journal of Geophysical Research Space Physics 118 7810-7821

Rostoker G, Akasofu S-I, Foster J, Greenwald R, Kamide Y, Kawasaki K, Lui A, McPherron R L and Russell C T (1980) Magnetospheric substorms - definition and signatures in J Geophys Res $\mathbf{8 5}$ 1663-1668

Ruddiman W and McIntyre A (1976) Northeast Atlantic paleoclimatic changes over the past 600,000 years Geological Society of America Memoirs 145 111146

Seppälä A, Randall C E, Clilverd M A, Rozanov E and Rodger C J (2009) Geomagnetic activity and polar surface air temperature variability in J Geophys Res 114 A10312 doi: 10.1029/2008JA014029

Seppala A, Clilverd M A and Rodger C J (2007) Nox enhancements in the middle atmosphere during 2003 \{2004 polar winter: Relative signi_cance of solar proton events and the aurora as a source Journal of Geophysical Research: Atmospheres 112

Siingh D, Singh R P, Gopalakrishnan V, Selvaraj C and Panneerselvam C (2013) Fair-weather atmospheric electricity study at Maitri (Antarctica) Earth, Planets and
Space 65 1541-1553

Singh A K, Behera J K, Dhar A, Saini S, Panneerselvam C and Sinha A K (2016) Morphology of the auroral electrojets over Maitri station (magnetic latitude $63^{\circ} \mathrm{S}$ ) Scientific Report of Antarctica XXVIII ISEA, Technical Report (submitted)

Singh A K, Jayashree B, Sinha A K, Rawat R, Pathan B M and Dhar A (2011) Observations of near-conjugate high latitude substorms and their low latitude implications in Current Science 101 1073-1078

Singh A K, Sinha A K, Rawat R, Jayashree B, Pathan B M and Dhar A (2012) A broad climatology of very high latitude substorms in Adv Space Res 50 1512-1523 doi: 10.1016/ j.asr.2012.07.034

Singh A K, Sinha A K, Saini S and Rawat R (2015) Auroral electrojets during severely disturbed geomagnetic condition on 24 August 2005 in Adv Space Res 55 1349-1355

Stauning P (1996) Investigations of ionospheric radio wave absorption processes using imaging riometer techniques $J$ Atmosp Terr Phys 58 753-764

Sunil P S, Reddy C D, Ponraj M, Dhar A and Jayapaul D (2007) GPS determination of the velocity and strain-rate fields on Schirmacher Glacier, central Dronning Maud Land, Antarctica Journal of Glaciology 53 558-564

Sunil P S and Reddy C D (2008) Tide-induced Nivlisen Ice Shelf Movement, East Antarctica, from GPS Observations (2008) Proceedings, International Workshop on Snow, Ice, Glacier and Avalanches 1 122-129

Tanskanen E I (2009) A comprehensive high-throughput analysis of substorms observed by IMAGE magnetometer network: Years 1993-2003 examined in J Geophys Res 114 A05204 doi: 10.1029/2008JA013682

Tsurutani B T, Hajra R, Echer E and Gjerloev J W (2015) Extremely intense (SML $\geq-2500 \mathrm{nT})$ substorms: isolated events that are externally triggered? in Ann Geophys $\mathbf{3 3}$ 519-524 doi: 10.5194/angeo-33-519-2015

Turunen E, Verronen P T, Seppala A, Rodger C J, Clilverd M A, Tamminen J, Enell C F and Ulich T (2009) Impact of different energies of precipitating particles on nox generation in the middle and upper atmosphere during geomagnetic storms Journal of Atmospheric and SolarTerrestrial Physics 71 1176-1189

Vichare G, Rawat R, Hanchinal A, Sinha A K, Dhar A and Pathan B M (2012) Seasonal evolution of $S_{\mathrm{q}}$ current system at sub-auroral latitude Earth Planet Sp (2012) 641023. doi: 10.5047/eps.2012.04.007

Victor N J, Panneerselvam C and Kumar C P A (2015) Variation of surface electric field during geomagnetic disturbed period 
at Maitri, Antarctica Journal of Earth System Science $\mathbf{1 2 4}$ 1721-1733

Victor N J, Manu S, FrankKamenetsky A V, Panneerselvam C, Anil Kumar C P and Elango P (2016) Network of observations on the atmospheric electrical parameters during geomagnetic storm on 5 April 2010 J Geophys Res
Space Physics 121 2407-2417 doi: 10.1002/ 2015JA022080

Wilson C T R (1921) Investigations on lightning discharges and on the electric field of thunderstorms Philosophical Transactions of the Royal Society of London. Series A, Containing Papers of a Mathematical or Physical Character 221 73-115. 